\title{
Spatial Variations of B-Value and Fundamental Parameters of The Earthquake Occurrences in The Eastern Mediterranean and Caucasus
}

\section{Bahruz Ahadov ( $\sim$ geofizik608@mail.ru )}

Peking University https://orcid.org/0000-0002-4608-8138

\section{Serkan Ozturk}

Gumushane University: Gumushane Universitesi

\section{Research Article}

Keywords: Magnitude completeness(Mc), b-value, Stress variance, Hazard, Eastern Mediterranean, Caucasus

Posted Date: April 27th, 2021

DOI: https://doi.org/10.21203/rs.3.rs-321644/v1

License: (c) (i) This work is licensed under a Creative Commons Attribution 4.0 International License. Read Full License 


\title{
Spatial variations of $b$-value and fundamental parameters of the earthquake occurrences in the Eastern Mediterranean and Caucasus
}

\author{
Bahruz Ahadov 1,2,3* Serkan Ozturk ${ }^{4}$ \\ ${ }^{1}$ Shanghai Astronomical Observatory, Chinese Academy of Sciences, Shanghai 200030, \\ China \\ ${ }^{2}$ University of Chinese Academy of Sciences, Beijing 100049, China \\ ${ }^{3}$ School of Earth and Space Sciences, Peking University, Beijing 100871, China \\ ${ }^{4}$ Gümüşhane University, Department of Geophysics, TR-29100, Gümüşhane, Turkey \\ Email: geofizik608@mail.ru
}

\begin{abstract}
The Gutenberg-Richter (GR) law is a well-known empirical relation in seismology, which describes the frequency of earthquake occurrence as a function of the magnitude. The $b$-value anomalies may indicate the high or low-stress levels in the heterogeneity or the crust's thermal gradient. Some researchers have examined the spatial and temporal anomalies of the $b$-value before the mainshock and the aftershocks' spatial variability. The variations of the magnitude completeness $\left(M_{c}\right)$ have estimated from the different earthquake catalogues. The high-resolution map of the GR $b$-value, $M_{c}$ and stress variance have analysed in the different seismic regions in the Eastern Mediterranean and Caucasus. This study considered the spatial anomalies and correlation models between the $b$-value, faulting styles, and stress regime and moment release. Lower $b$-values ( $b \leq 1)$ were observed along with the Main Marmara Fault (MMF), eastern Turkey, western Alborz, northern Zagros, southeast Iran and the northeast Caucasus, which indicates the active seismic region. The $M_{c}$ level in most of Turkey is in and around 2.8, and in the Caucasus is $M_{c}=3$, while Iran has $M_{c}=3.5$ value. This work includes a stress inversion map in the region based on the focal mechanisms. The normal, strike-slip and a few thrust fault solutions were observed in
\end{abstract}


the research area. Consequently, the spatial pattern of the $b$-values and stress regime can be used as a tool for predicting the forthcoming seismic hazard regions.

Keywords: Magnitude completeness $\left(M_{c}\right) ; b$-value; Stress variance; Hazard; Eastern Mediterranean; Caucasus.

\section{Introduction}

The Eastern Mediterranean and Caucasus are complex tectonic active regions associated with major lithospheric plates, Eurasian, Arabian, Nubia and Somalia (McKenzie, 1970; McKenzie, 1972) (Fig.1). The Eastern Mediterranean connected in the interaction zone of the Arabian, the Eurasian and Anatolian plates to the westward from the various intense convergence zone (Wdowinski et al., 2004). The plate motion includes thrust faults related to the Caucasus and the eastern Anatolian. The tectonic development of the region was formed by continental collision in the east of Turkey and subduction in Greece (Hellenic) (Jackson and McKenzie, 1984; Le Pichon and Angelier, 1979). The Anatolian block is placed among the African and Eurasian, and the Arabian plates since the collision (Jackson and McKenzie, 1984; McKenzie, 1972). The main tectonic settings of central Anatolian include intraplate pull basins and strike-slip faults. The North Anatolian Fault (NAF) describes the northern boundary with the Eurasian plateau, including a principal strike-slip fault (Barka and Kadinsky-Cade, 1988).

Previous studies have quantified regional deformation in interplay zone of the plate in the region (Ahadov and Jin, 2017, 2021; Aktuğ et al., 2013; Alchalbi et al., 2010; Mahmoud et al., 2005; McClusky et al., 2000; Meade et al., 2002). During history, the Mediterranean region has been hit by various destructive earthquakes. The seismicity of Turkey is different from Iran, as there are significant earthquakes in areas far from the three belts. Seismic activity in the western Anatolia was the most unusual geodynamic features in the region. There have been 
large earthquakes with the magnitude of $M w \geq 6$ due to historical seismic activity in the region (Table 1).

Many statistical studies have investigated the seismicity in distinct regions. (Mousavi, 2017b; Öztürk, 2015; Telesca et al. 2017; Öztürk, 2018). The seismic activity can present essential and reliable information about the stress concentration of earthquakes and Earth's formation in the region. The $M c$ value is an essential parameter for most questions related to seismicity. The $M_{c}$ changes over time depending on the techniques of investigation and the number of seismic stations. The $b$-value can be implemented to evaluate the seismic hazard in a region to classify the stress. Therefore, the relationship between earthquakes and differences in the value of $b$ is playing a role in earthquake prediction. High $b$-value is observed around volcanic chambers and while low $b$-value in the grooves section (Wiemer and Wyss, 2002). Many studies have noted that the value of $b$ changes due to stress and heterogeneity in the crust (e.g. Khan and Chakraborty, 2007; Mogi, 1962; Mousavi, 2017b; Scholz, 1968; Wiemer and Katsumata, 1999; Wyss, 1973). The range of $b$-values between 0.3-2 has been published concerning tectonic events ( Schorlemmer et al., 2005; Utsu, 1971). Earthquakes can be associated with energy release relevant to the fault dimensions, slip, and stress drop. The theory has been explained that measuring the magnitude of earthquake quantities and the results of the destruction (Kanamori, 1983).

The significance of this study is that the spatial model of $b$-value and seismotectonic features and their relation to tectonic settings in the Eastern Mediterranean and Caucasus have analysed. This study contributes a high-resolution map of the $b$-value between the released seismic moments, the fault mechanism, and the stress variability, which is the most relevant and integral part of seismicity. The conclusions can contribute significant constraints on crustal stress and hazard assessment in the region. 


\section{Data and Methods}

The mapped $b$-value of the recurrence magnitude relationship of earthquakes from the background seismicity catalogues was based on $M l$ scale that was recorded by Kandilli Observatory, Earthquake Research Institute (KOERI, www.koeri.boun.edu.tr/sismo), International Seismological Centre (ISC, www.isc.ac.uk/iscbulletin) and International Institute of Earthquakes Engineering and Seismology (IIEES, www.iiees.ac.ir/en) from 1998 to 2020 ( $M_{l} \geq 1$, Fig. 2) in the Turkey, Caucasus and Iran, respectively. In order to provide the frequency of earthquakes in the G-R relation, the first determined clusters and separate dependent events from the catalogues. The extent of earthquakes in the catalogue shows an almost linear increase over time. The relation between the amplitude of shock and the effects correlated with its existence called FMD, has been defined as (Gutenberg and Richter, 1944):

$$
\log _{10} N(M)=a-b M
$$

$N$ is the number of events with a given magnitude $M$ while $a$ and $b$ are constants, the constant $a$ is related to the earthquake activity.

Wiemer and Wyss (1997) showed that low $b$-value along a fault zone corresponds to the features that regulate earthquake behaviour. $M c$ is determined at every grid node using the Best Combination approach (Wiemer, 2001) in the study region. The $M_{c}$ value's standard deviation was achieved using the Bootstrapping process proposed by Schorlemmer et al., (2005).

The maximum likelihood relationship of G-R applied to calculate $b$-value, which has been observed more positive correlation with tectonic formations (Aki, 1965). Moreover, low stress has experienced in the seismogenic zone inducing episodic variations in the tectonic area (Wyss, 1973). The maximum likelihood approach provides a robust calculation of $M c$ in most cases and can be expressed as (Wiemer and Wyss, 1997):

$$
\mathrm{b}=\frac{\log _{10} \mathrm{e}}{\left(\mathrm{M}_{\text {mean }}-\mathrm{M}_{\min }\right)}
$$

$M_{\text {mean }}$ is mean value of magnitude and $M_{\text {min }}$ is the minimum rate of the completeness in the catalogues. The uncertainty of this assessment is provided by Eq. (3) as proposed by Shi and Bolt (1982): 


$$
\sigma(b)=2.30 b^{2} \sqrt{\sum_{i=1}^{n}\left(M_{i}-M_{\text {mean }}\right) / n(n-1)}
$$

where $n$ is the complete number of events in the catalogue.

Earthquakes were collected from distinct catalogues and applied the corresponding interpolation technique (Wiemer and Wyss, 1997) to characterise the spatial accumulation value of $b$. The investigation is conducted on non-declustered and declustered catalogues. For each region, created a $b$-value map using the radius $R_{\max }=80,90,140 \mathrm{~km}$ and determined $b$ value if at least $R_{\min }=20,15$ and 15 events were available for individual grid node in Turkey, Caucasus and Iran, respectively. A bootstrap approach implemented to consider the reliability and quality of the $b$-value and Mc results. The number of events detected using $0.1^{0} \times 0.1^{0}$ grid node to compute the $M_{c}$ and $b$-value, the density of data providing multiple events to be selected.

Different stress inversion techniques have been used to estimate the stress direction of the earthquake focal mechanism. Well-known methods of Gephart and Forsyth (1984) and Michael (1984) intend to determine the stress which minimizes the difference between the defined shear stress direction and the slip rate for a particular dataset. These algorithms explain the direction of the major stress arrows and the appropriate dimensions of stress, $\mathrm{R}=$ $\left(\sigma_{2}-\sigma_{3}\right) /\left(\sigma_{1}-\sigma_{3}\right)$. Here, $\sigma_{1}, \sigma_{2}, \sigma_{3}$ symbolises maximum, intermediate and minimum principal compressive stress, respectively.

In this study, stress inversion has produced using Michael's method. In a slick rule of Michael (Michael, 1984) the stress tensor is calculated applying a linear least-squares inversion technique. The algorithm uses each nodal planes to classify the fault plane while obtaining a particular stress tensor accurately. The algorithm's critical point is to determine the confidence threshold for the orientation of the principal stress arrows. Reliability thresholds have calculated by adopting a statistical tool known as bootstrap resampling. Maps of stress regime and variance have figured using six events per node with $0.2^{0} x 0.2^{0}$ grid range.

In addition, estimated the seismic moment $\left(M_{0}\right)$ from moment magnitude $\left(M_{w}\right)$ to understand the stress accumulation by applying the standard relation from Kanamori and Brodsky (Kanamori and Brodsky, 2001),

$$
\log M_{0}=1.5 M_{w}+9.1
$$

140 Different methods compute diverse scales of the magnitude and have other saturation states.

We used an empirical relationship with additional references (Kadirioğlu and Kartal, 2016; 
Mousavi-Bafrouei et al., 2015) to convert various magnitude scales ( $M l$ to $M w)$ in each database.

\section{Results and discussions}

\subsection{Magnitude of completeness $\left(M_{c}\right)$}

The actual estimation rate of $b$-value depends on the completeness of the magnitude $\left(M_{c}\right)$. $M c$ is changing between time and space, with the earthquake catalogues and involves its assessment. Evaluation of earthquake completeness catalogues is an essential step to learn in all seismicity (Woessner and Wiemer, 2005). The variability of $M c$ depends on the seismic activity and sensitivity of stations. The $M c$ is a fundamental parameter for all seismic processing and may create an error while estimating the $b$-value because of the heterogeneity of $M c$ values in the area. Since the study area is seismically active, $M c$ is estimated based on the combined frequency-magnitude database. From the $M c$ map, it is seen that KOERI catalogue in most of Turkey is resolved to $M c=2.8$, in most of Caucasus the completeness level is at $M c=3$ from ISC catalogue, and in the IIEES catalogue of Iran it is $M c=3.5$ (Fig.3). Most of the areas were observed within the standard deviation of 0-0.1 in Iran and Turkey, while the Caucasus is associated with higher errors $\sim 0.3$. Determination of $M c$-value is desirable since most applications demand many decisions when defining parameters such as seismicity rate or $b$-values (Wiemer, 2001).

\section{2 b-value}

The value of $b$ is considered correlated with developed heterogeneity of stress on the crust (Mogi, 1962; Wiemer and Wyss, 1997) and a range of 0.5-1.5 (or with the error limits, between 1.30 and 1.64) for tectonic earthquakes (Olsson, 1999). Several researchers (Mousavi 2017a; Öztürk 2011) have investigated spatial differences of $b$ in the different seismic regions. Öztürk (2011) evaluated seismic activity from several earthquake catalogues with an 
average ( 1) variations on diverse segments along the NAF. The map displays (Fig. $4 \mathrm{a}, \mathrm{b}$ ) of the calculated $M c$ and $b$-values from non-declustered and declustered catalogues using a smaller radius with higher resolution. The epicentre of earthquakes is associated with lowvalue areas $(b<1)$. The $b$-values are observed mainly less than one in Izmit, Erzurum and Van. Low value ranges coincided by the spatial distribution in rupture area of earthquakes. However, some cases have been considered in a good relationship between the $b$-values and the rupture zone that occurred in 1999 the Izmit and in 2011 the Van earthquakes.

Mousavi (2017a) described the relationship between the moment release and $b$-value in Iran between 2006-2016. The calculated values were observed between 0.8-1.5. Higher values were observed in eastern and central Iran, while lower rates change in the northern Tabriz and central Alborz. The calculated $b$-values of this study mainly ranged between $0.2-1.5$ in Iran (Fig. 5a, b). Due to significant tectonic stress and local variations on plate tectonic activity, lower rates (below 1) observed in westernmost Kermanshah, southern Bam and eastward Alborz. We see that larger values prevail in SSW Zagros, northern Kermanshah, and central Iran. The value of $b$ in the northwestern Alborz region and Mashhad is close to the hypothesis that seismic energy falls for further severe earthquakes. The low value in the western Kermanshah is reasonable to be a significant change in the Zagros region on the Iraqi-Iranian border, has reported in the 2017 Sarpol-e Zahab earthquake. There are transparent connections between high values from small earthquakes and dense fractures. Low values in some areas indicate that mainly large-scale earthquakes were released energy.

The spatial mapping of the $b$ value can investigate the seismotectonics of the region. A recent study was used local network data by Telesca et al. (2017) found that higher values were varied between 0.9-1.2 in the south and that lower value variation was observed in northern Azerbaijan. In this study, the value of $b$ estimated from different methods and data applying declustered and non-declustered catalogues is more consistent with previous studies in a wide 
area. The rates in the Caucasus generally range between 0.6-1.7. The current trends show that higher values (1.3-1.6) in Armenia while lower values (below 0.8) were observed in Zaqatala, Oghuz and Shamakhi along the MCTF in Azerbaijan (Fig. 6 a, b). Higher values may be correlated with less intensive rocks that encounter inelastic failure at under stress levels.

Besides, the $b$-values were learned in depth (Fig. 7). The maximum value observed at a depth of $14 \mathrm{~km}$ in Iran. We can also see that the low values $(b<1)$ were at $15-40 \mathrm{~km}$ and a sharp increase at $33 \mathrm{~km}$ depth. A higher value was observed at a depth of $6 \mathrm{~km}$ in Turkey. The sharp variations between $\sim 1.1$ and 1.6 are also present in the Caucasus at a depth of $12 \mathrm{~km}$. The depth of $b$ value gives us a model of stress accumulation at different depths.

Fig. 8 describes that the b-values are extending from 0.6 to 2 along the main faults. The profile (C-C') shows the highest values at a depth of 20-25 km along the EAF. When high values are loaded with cracks, the response to the existing fault cracks reduces large earthquakes due to the collapse (Wiemer and Wyss, 2000). An impressive observation involves low-value areas in the southern Bitlis-Zagros and the eastward Greater Caucasus, indicating high stress in the area. The low value was seen along the Marmara (E-E') at $20 \mathrm{~km}$. A lower value in the seismogenic zone has been agreed with a significant reduction in stress levels before the mainshock (Kanamori, 1981).

\subsection{Stress Tensor Inversion}

In this study, a total of 1020 Focal Mechanism Solutions were selected from the Global Centroid Moment Tensor database. The spatial occurrence of earthquakes suggests that the data has sufficient resolution to indicate the stress regime and measure the variability in the region. The distribution of the earthquakes is linked to the combination of existing faults, and these mechanisms are compatible with the understanding of changes along the faults. The $b$ values usually vary with the source mechanism of the earthquakes. The highest values confirm 
normal fault events, average values indicate strike-slip events, and the lowest values show

217 thrusts events, respectively (Schorlemmer et al., 2005). Fig. 9 reveals the colour bars displaying horizontal compression directions and associated tectonic structures. In addition to normal faults, some areas have a complex strike-slip fault, such as western Anatolian, some parts of the Caspian Sea and south-eastern Iran. The low $b$-values indicate regions, including strike and inverse slip faults corresponding to the features of the tectonic zone. It is an essential consequence of $b$ closer to a low value in Turkey, the Great Caucasus, Zagros, Kopet-Dagh and eastern Alborz. These zones are associated with the thrust and strike-slip faulting, which is under a higher stress regime. Stress variability in the region is also different in several areas (Fig. 10). The stress variance is completely under this limit except for the confined area of the study region. The variation map shows that highly variable areas overlap with high $b$-values and correlates with low-stress variability and where the variance is less than 0.2 . The stress difference is more than 0.2 means a different stress area or a decreased resolution of data.

\subsection{Comparison with seismic moment release}

Most of the area leads to a correlation between the $b$-value and the seismic moment's release. The seismic moment release (Fig.11) was calculated on each grid node with an interval of $0.5^{0} \times 0.5^{0}$ and compared with the $b$-value map. A lower value variation and higher moment release were observed in Izmit, Van and Erzurum, which indicates the location of high-stress zones. The Eastern Caucasus have intermediate value changes with an average moment release. 


\section{Conclusion}

In this study, the spatial changes of the $b$-value were evaluated by analysing earthquake events within 1998-2020 years from the different catalogues such as the ISC, KOERI and IIEES. The investigation of seismicity is essential for evaluating seismic hazards and a better understanding of the different tectonic features in the seismogenic zone. The estimated completeness of the magnitude level is 2.8 in most of Turkey, $M_{c}=3$ in the Caucasus, and it was observed 3.5 in Iran. $b$-value was investigated by the time and space up to a wide variety of long-term and different earthquake catalogues. Obtained results from the non-declustered and declustered catalogues are better correlated with other $b$-value studies in the geodynamics and structure of the region. Higher values were found in the western Turkey, eastern and central Iran and the south western Caucasus. In certain areas, lower values were associated with extensive faulting result in low heterogeneity and large earthquakes. The $b$-value is not only indicated the relative size of small and large earthquakes also related to the stress state over the region. The $b$-values characterised the earthquakes and stayed around one. Therefore, it may be assumed that most of the region is low value and seismically active. Completed results are coherent with the tectonic formation of the area when the overall region was considered. Mainly strike-slip movements and the principal stress directions support the adjustment of the focal mechanisms. The low and medium $b$-values in the region are under the impact of the tectonic process from the African, Arabian and Eurasian Plates presented by the strike and thrust slip deformations. The $b$-value mapping is a relevant tool for displaying different levels of stress across large areas. As a result, a massive earthquake has occurred in the high-stress areas (low-value), and there was no significant earthquake in the high-value areas. Therefore, spatial maps of the $b$-values and stress mode maps can be appropriated as a tool for consequent seismic hazard and earthquake zones. 


\section{Acknowledgement}

All the maps are drawn using Generic Mapping Tools (GMT) (Wessel et al., 2013), and the graphs are plotted using ZMAP (Wiemer, 2001). This research did not receive any specific grant from funding agencies in the public, commercial, or not-for-profit sectors.

\section{Conflicts of interest/Competing interests}

The authors declare no conflict of interest.

\section{Ethics approval}

Authors are responsible for the reliability of the manuscript and collaborate with the Editorial Office when original pictures and data, and other proof materials are required.

\section{References}

Ahadov, B., Jin, S., 2017. Present-day kinematics in the Eastern Mediterranean and Caucasus from dense GPS observations. Physics of the Earth and Planetary Interiors 268, 54-64.

Ahadov, B. and Jin, S., 2021. Slip Rates and Seismic Potential Along Main Faults in the Eastern Mediterranean and Caucasus from dense GPS Observations and Seismic Data. Pure and Applied Geophysics, pp.1-16.

Aki, K., 1965. Maximum likelihood estimate of $\mathrm{b}$ in the formula $\log \mathrm{N}=\mathrm{a}-\mathrm{bM}$ and its confidence limits. Bull. Earthq. Res. Inst., Tokyo Univ. 43, 237-239.

Aktuğ, B., Parmaksız, E., Kurt, M., Lenk, O., Kılıçoğlu, A., Gürdal, M.A., Özdemir, S., 2013. Deformation of Central Anatolia: GPS implications. Journal of Geodynamics 67, 78-96.

Alchalbi, A., Daoud, M., Gomez, F., McClusky, S., Reilinger, R., Romeyeh, M.A., Alsouod, A., Yassminh, R., Ballani, B., Darawcheh, R., 2010. Crustal deformation in northwestern Arabia from GPS measurements in Syria: Slow slip rate along the northern Dead Sea Fault. Geophysical Journal International 180, 125-135. 
Barka, A., Kadinsky-Cade, K., 1988. Strike-slip fault geometry in Turkey and its influence on

290

291

292

293

294

295

296

297

298

299

300

301

302

303

304

305

306

307

308

309

310

311

312 earthquake activity. Tectonics 7, 663-684.

Gephart, J.W., Forsyth, D.W., 1984. An improved method for determining the regional stress tensor using earthquake focal mechanism data: application to the San Fernando earthquake sequence. Journal of Geophysical Research: Solid Earth 89, 9305-9320.

Gutenberg, B., Richter, C.F., 1944. Frequency of earthquakes in California. Bulletin of the Seismological Society of America 34, 185-188.

Jackson, J., McKenzie, D., 1984. Active tectonics of the Alpine-Himalayan Belt between western Turkey and Pakistan. Geophysical Journal International 77, 185-264.

Kadirioğlu, F.T., Kartal, R.F., 2016. The new empirical magnitude conversion relations using an improved earthquake catalogue for Turkey and its near vicinity (1900-2012). Turkish Journal of Earth Sciences 25, 300-310.

Kamer, Y., Hiemer, S., 2015. Data-driven spatial b value estimation with applications to California seismicity: To b or not to b. Journal of Geophysical Research: Solid Earth 120, 51915214.

Kanamori, H., 1981. The nature of seismicity patterns before large earthquakes.

Kanamori, H., 1983. Magnitude scale and quantification of earthquakes. Tectonophysics 93, 185-199.

Kanamori, H., Brodsky, E.E., 2001. The physics of earthquakes. Physics Today 54, 34-40.

Khan, P., Chakraborty, P.P., 2007. The seismic b-value and its correlation with Bouguer gravity anomaly over the Shillong Plateau area: tectonic implications. Journal of Asian Earth Sciences $29,136-147$.

Le Pichon, X., Angelier, J., 1979. The Hellenic arc and trench system: a key to the neotectonic evolution of the eastern Mediterranean area. Tectonophysics 60, 1-42. 
Mahmoud, S., Reilinger, R., McClusky, S., Vernant, P., Tealeb, A., 2005. GPS evidence for northward motion of the Sinai Block: implications for E. Mediterranean tectonics. Earth and Planetary Science Letters 238, 217-224.

McClusky, S., Balassanian, S., Barka, A., Demir, C., Ergintav, S., Georgiev, I., Gurkan, O.,

Hamburger, M., Hurst, K., Kahle, H., 2000. Global Positioning System constraints on plate kinematics and dynamics in the eastern Mediterranean and Caucasus. Journal of Geophysical Research: Solid Earth 105, 5695-5719.

McKenzie, D., 1970. Plate tectonics of the Mediterranean region. Nature 226, 239-243.

McKenzie, D., 1972. Active Tectonics of the Mediterranean Region. Geophysical Journal International 30, 109-185.

Meade, B.J., Hager, B.H., McClusky, S.C., Reilinger, R.E., Ergintav, S., Lenk, O., Barka, A.,

Özener, H., 2002. Estimates of seismic potential in the Marmara Sea region from block models the Seismological Society of America 92, 208-215.

Michael, A.J., 1984. Determination of stress from slip data: faults and folds. Journal of Geophysical Research: Solid Earth 89, 11517-11526.

Mogi, K., 1962. Magnitude-frequency relation for elastic shocks accompanying fractures of various materials and some related problems in earthquakes. Bull. Earthq. Res. Inst., Univ. Tokyo 40, 831-853.

Mousavi-Bafrouei, S.H., Mirzaei, N., Shabani, E., 2015. A declustered earthquake catalog for the Iranian Plateau. Annals of Geophysics 57.

Mousavi, S.M., 2017a. Mapping seismic moment and b-value within the continental-collision orogenic-belt region of the Iranian Plateau. Journal of Geodynamics 103, 26-41. 
Mousavi, S.M., 2017b. Spatial variation in the frequency-magnitude distribution of earthquakes under the tectonic framework in the Middle East. Journal of Asian Earth Sciences 147, 193-209.

Olsson, R., 1999. An estimation of the maximum $b$-value in the Gutenberg-Richter relation.

340 Geodynamics, 27, 547-552.

Öztürk, S., 2011. Characteristics of seismic activity in the Western, Central and Eastern parts of the North Anatolian Fault Zone, Turkey: Temporal and spatial analysis. Acta Geophysica 59, 209-238.

Öztürk, S., 2015. A study on the correlations between seismotectonic b-value and Dcvalue, and seismic quiescence Z-value in the Western Anatolian region of Turkey. Austrian Journal of Earth Sciences 108.

347 Öztürk, S., 2018. Earthquake hazard potential in the Eastern Anatolian Region of Turkey: seismotectonic $\mathrm{b}$ and Dc-values and precursory quiescence Z-value. Frontiers of earth science $12,215-236$.

Scholz, C., 1968. The frequency-magnitude relation of microfracturing in rock and its relation to earthquakes. Bulletin of the seismological society of America 58, 399-415.

Schorlemmer, D., Wiemer, S., Wyss, M., 2005. Variations in earthquake-size distribution across different stress regimes. Nature 437, 539.

Shi, Y., Bolt, B.A., 1982. The standard error of the magnitude-frequency b value. Bulletin of the Seismological Society of America 72, 1677-1687.

Telesca, L., Kadirov, F., Yetirmishli, G., Safarov, R., Babayev, G. and Ismaylova, S., 2017. of Seismology, 21(6), pp.1467-1485. 
Utsu, T., 1971. Aftershocks and earthquake statistics (2): further investigation of aftershocks and other earthquake sequences based on a new classification of earthquake sequences. Journal of the Faculty of Science, Hokkaido University. Series 7, Geophysics 3, 197-266.

Wdowinski, S., Bock, Y., Baer, G., Prawirodirdjo, L., Bechor, N., Naaman, S., Knafo, R., Forrai, Y., Melzer, Y., 2004. GPS measurements of current crustal movements along the Dead Sea Fault. Journal of Geophysical Research: Solid Earth 109.

Wessel, P., Smith, W.H., Scharroo, R., Luis, J., Wobbe, F., 2013. Generic mapping tools: improved version released. Eos, Transactions American Geophysical Union 94, 409-410.

Wiemer, S., 2001. A software package to analyze seismicity: ZMAP. Seismological Research Letters $72,373-382$.

Wiemer, S., Katsumata, K., 1999. Spatial variability of seismicity parameters in aftershock zones. Journal of Geophysical Research: Solid Earth 104, 13135-13151.

Wiemer, S., Wyss, M., 1997. Mapping the frequency-magnitude distribution in asperities: An improved technique to calculate recurrence times? Journal of Geophysical Research: Solid Earth 102, 15115-15128.

Wiemer, S., Wyss, M., 2000. Minimum magnitude of completeness in earthquake catalogs: Examples from Alaska, the western United States, and Japan. Bulletin of the Seismological Society of America 90, 859-869.

Wiemer, S., Wyss, M., 2002. Mapping spatial variability of the frequency-magnitude distribution of earthquakes, Advances in geophysics. Elsevier, pp. 259-V.

Woessner, J., Wiemer, S., 2005. Assessing the quality of earthquake catalogues: Estimating the magnitude of completeness and its uncertainty. Bulletin of the Seismological Society of America 95, 684-698.

Wyss, M., 1973. Towards a physical understanding of the earthquake frequency distribution. Geophysical Journal International 31, 341-359. 
Fig. 1 Tectonic and topographic/bathymetric map (SRTM30 plus) of the research area, including the interplay zone of the Eurasian, Arabian and Nubia plates. Abbreviations: AG (Aegean), NAF (North Anatolian Fault), EAF (East Anatolian Fault), DSTF (Dead Sea Transform Fault), NEAF (North-East Anatolian Fault), CF (Chalderan Fault), NTF (North

Tabriz Fault). Black beach balls represent the focal mechanism of the earthquakes $\left(\boldsymbol{M}_{\boldsymbol{w}} \geq \mathbf{5 . 5}\right.$, 1976-2020) from global Centroid Moment Tensor CMT).

Fig. 2 The map represents the distribution of the earthquakes in the study region (1998-2020).

Fig. 3 Frequency-magnitude number of earthquakes from. The solid line and triangle marked as best fit and magnitude of completeness.

Fig. 4 The maps of calculated $b$-value and $M c$ variations from non-declustered (upper) and declustered (bottom) catalogues for Turkey in the period of 1998-2020 from KOERI catalogue.

Fig. 5 The maps of calculated $b$-value and $M c$ variations from non-declustered (upper) and declustered (bottom) catalogues in the period 1998-2020 for Iran using IIEES catalogue.

Fig. 6 The maps of calculated $b$-value and $M c$ variations from non-declustered (upper) and declustered (bottom) catalogues in the period 1998-2020 in the Caucasus.

Fig. 7 The map shows the calculated value of $b$ and its error (horizontal bar) at a depth.

Fig. 8 Vertical mapping of $b$-values. The left line shows the intersections. In the middle line, a $b$-value of $150 \mathrm{~km}$ is given around each section. In the right line, the pattern of $b$-value is presented.

Figure 9 The direction of horizontal compression, different colors symbolize tectonic modes. Thrust).

Fig. 10 Horizontal compression orientation covered colored stress tensor variance map. 
408

409

410

411

412

Fig. 11 The map shows estimated moment release from the different catalogues from 1998 to 2020.

$24^{\circ} 26^{\circ} 28^{\circ} 30^{\circ} 32^{\circ} 34^{\circ} 36^{\circ} 38^{\circ} 40^{\circ} 42^{\circ} 44^{\circ} 46^{\circ} 48^{\circ} 50^{\circ} 52^{\circ} 54^{\circ} 56^{\circ} 58^{\circ} 60^{\circ} 62^{\circ} 64^{\circ}$

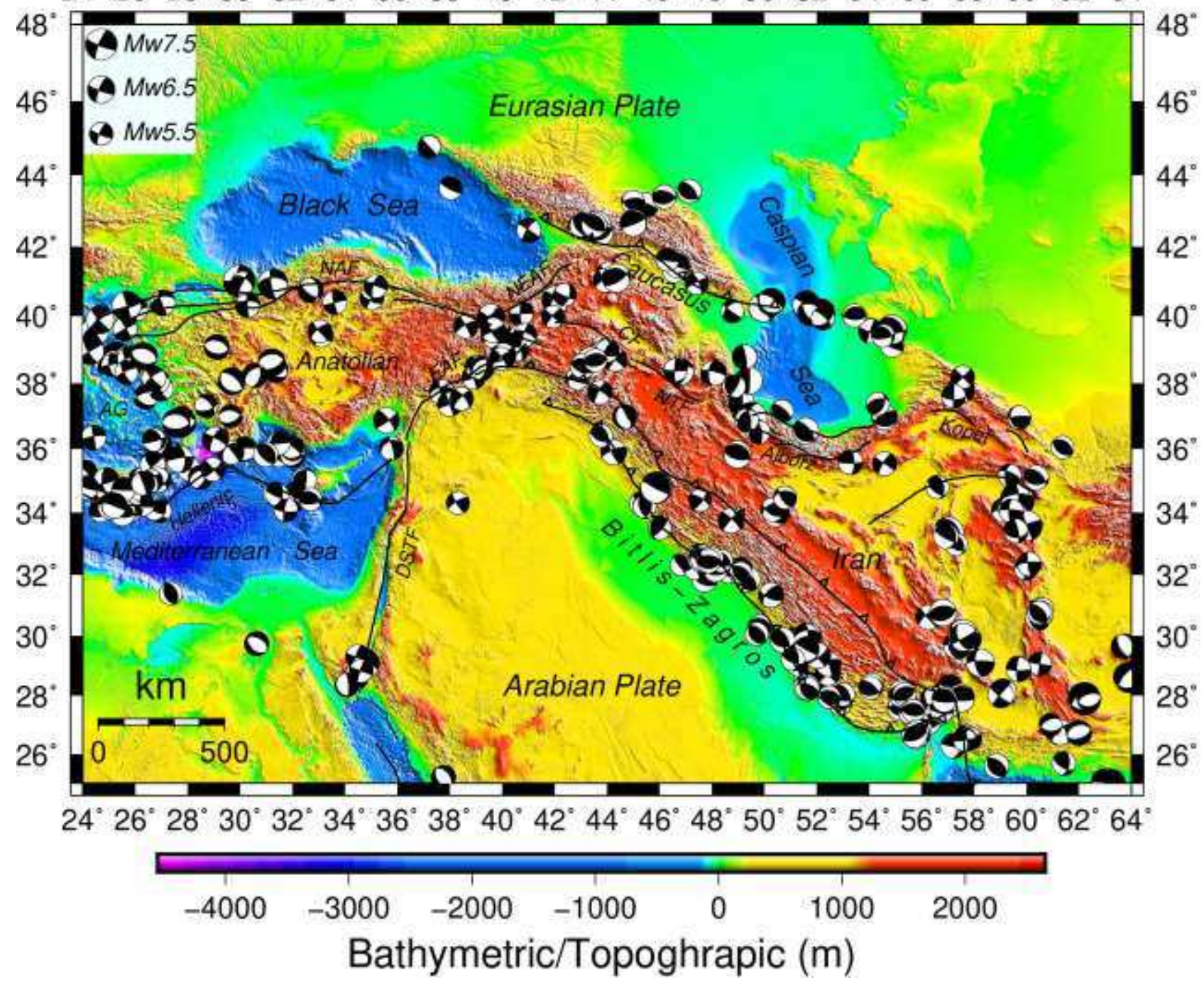

415 Fig. 1 Tectonic and topographic/bathymetric map (SRTM30 plus) of the research area, 416 including the interplay zone of the Eurasian, Arabian and Nubia plates. Abbreviations: AG 417 (Aegean), NAF (North Anatolian Fault), EAF (East Anatolian Fault), DSTF (Dead Sea 418 Transform Fault), NEAF (North-East Anatolian Fault), CF (Chalderan Fault), NTF (North 419 Tabriz Fault). Black beach balls represent the focal mechanism of the earthquakes $\left(\boldsymbol{M}_{\boldsymbol{w}} \geq \mathbf{5 . 5}\right.$, 420 1976-2020) from global Centroid Moment Tensor CMT). 


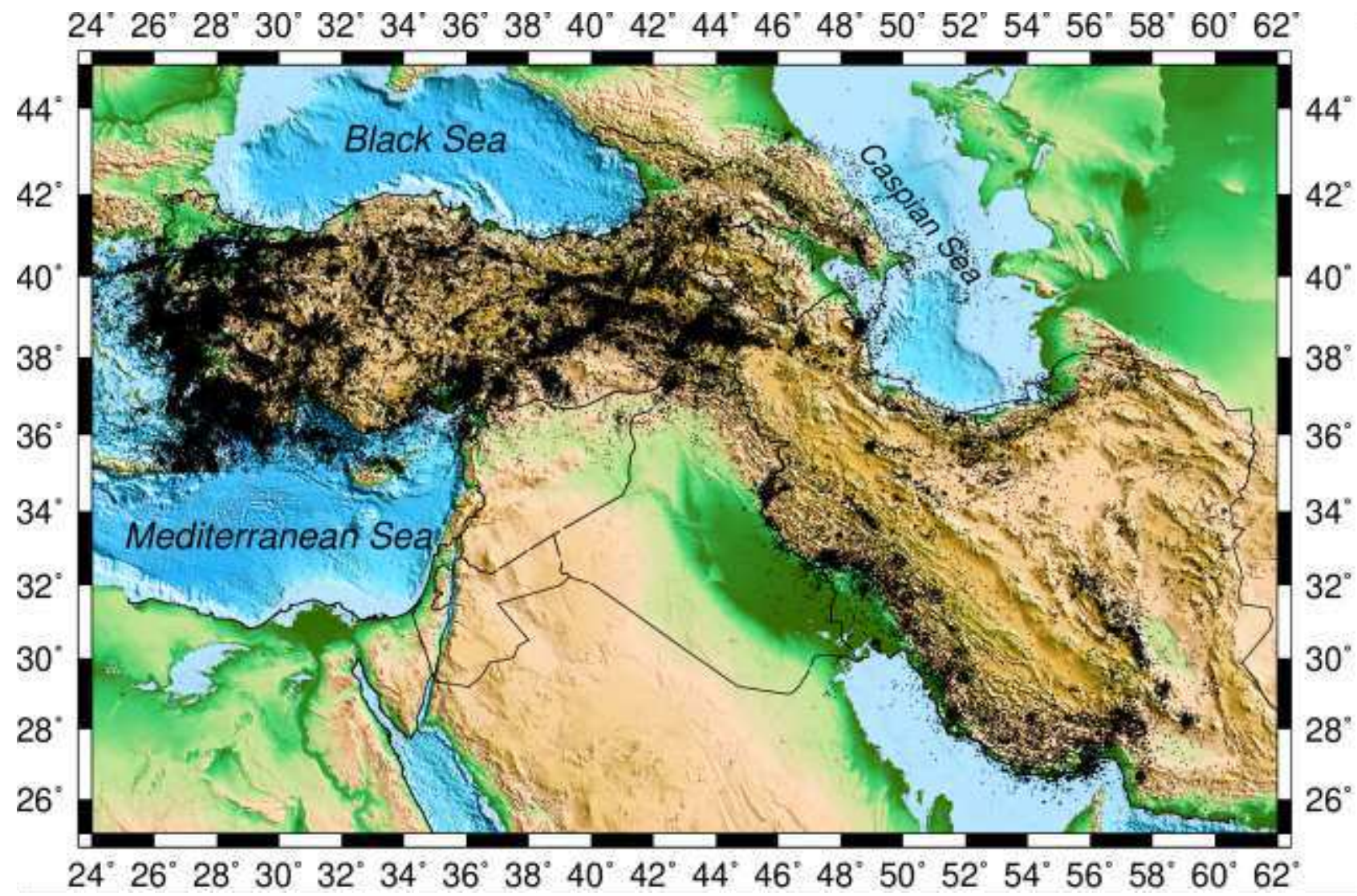

Fig. 2 The map represents the distribution of the earthquakes in the study region (1998-2020). 

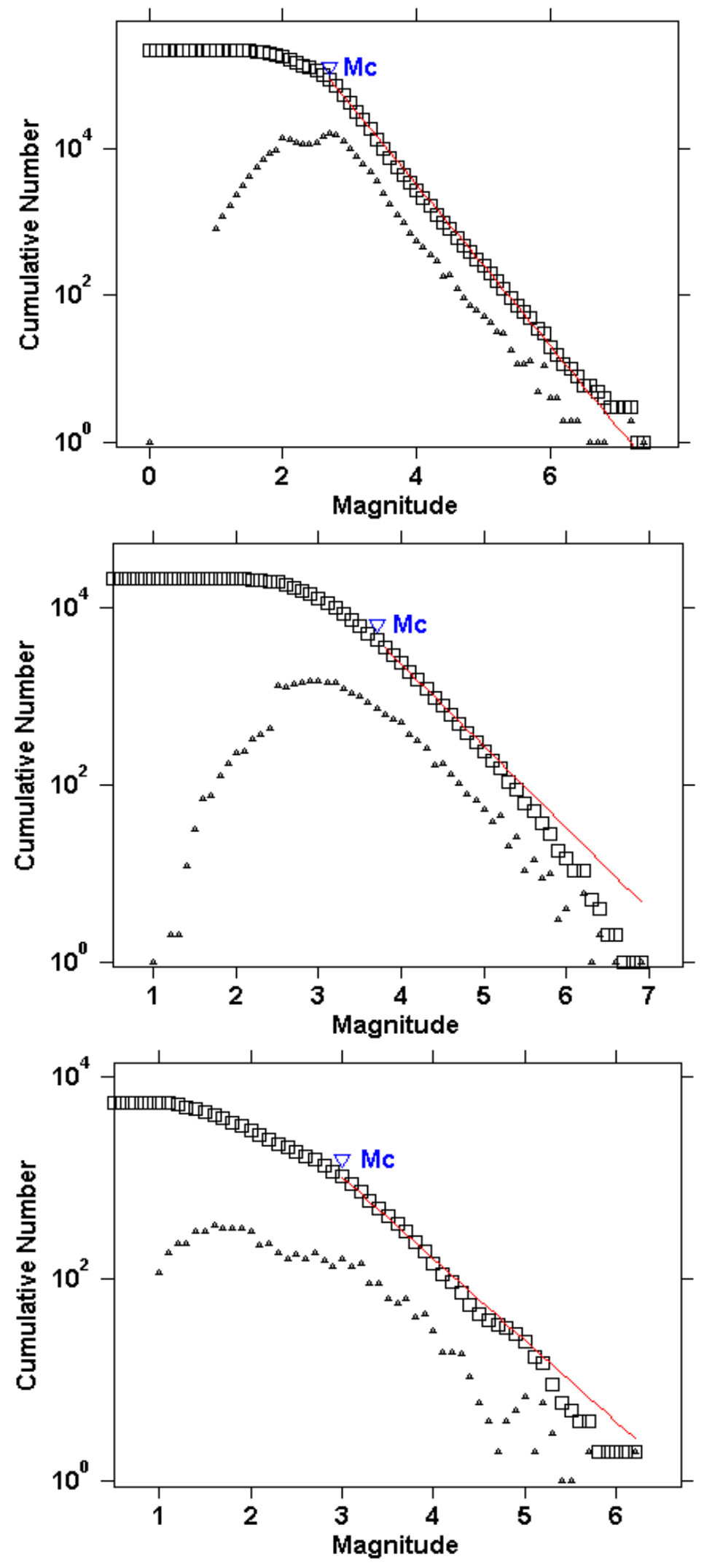

431 Fig. 3 Frequency-magnitude number of earthquakes from. The solid line and triangle marked $432 \quad$ as best fit and magnitude of completeness. 

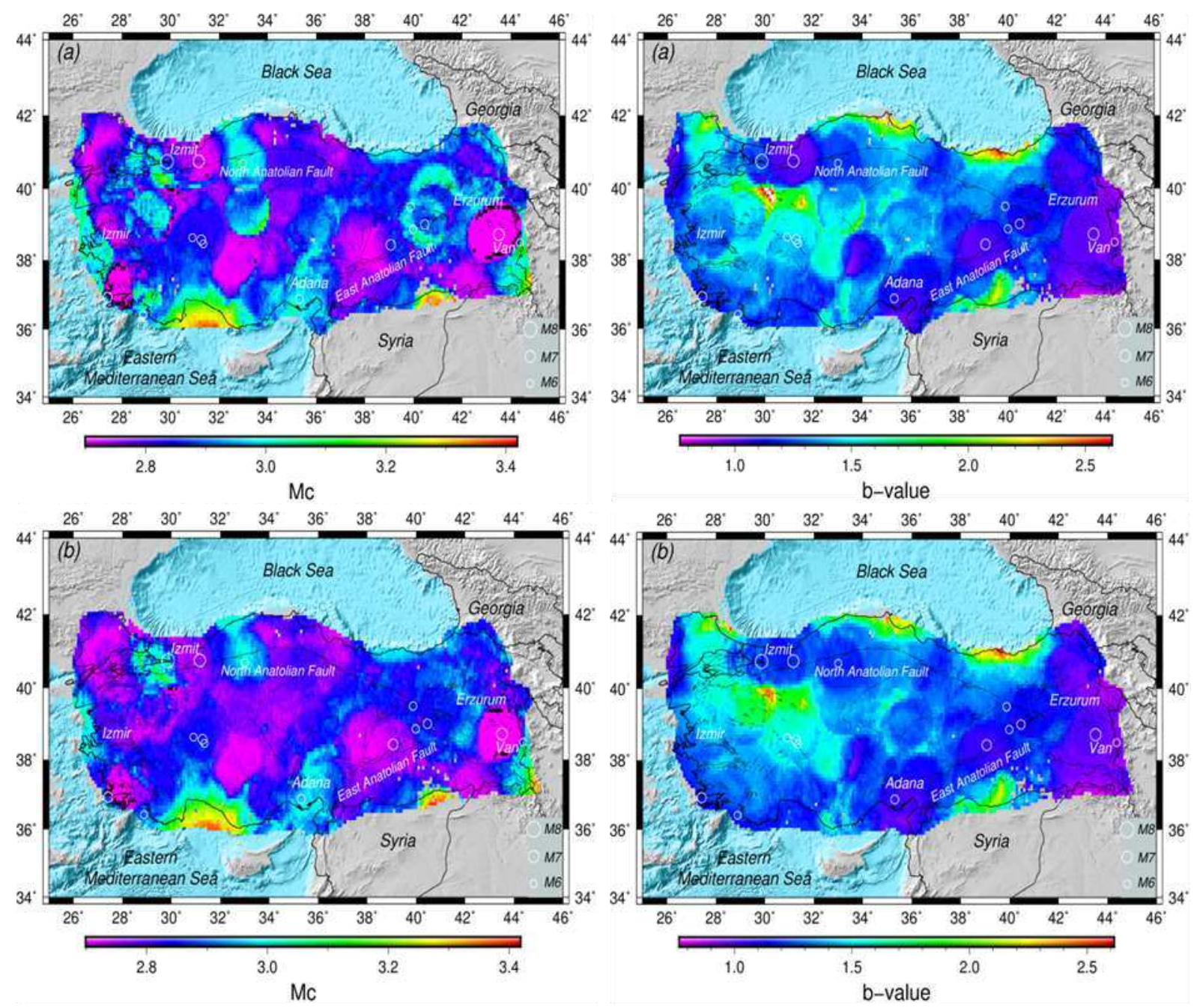

435 Fig. 4 The maps of calculated $b$-value and $M c$ variations from non-declustered (upper) and 

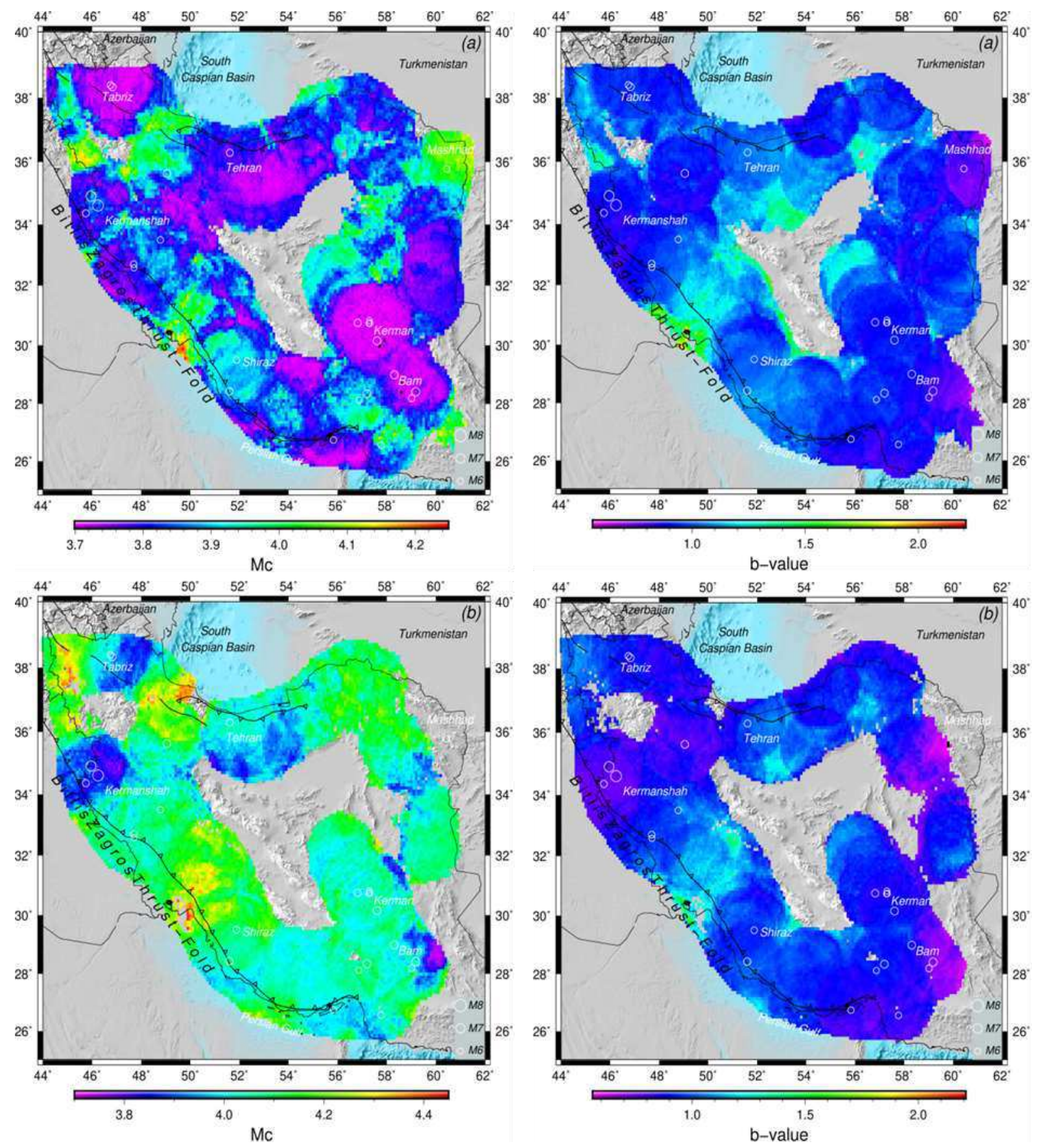

448 Fig. 5 The maps of calculated $b$-value and $M c$ variations from non-declustered (upper) and 449 declustered (bottom) catalogues in the period 1998-2020 for Iran using IIEES catalogue. 

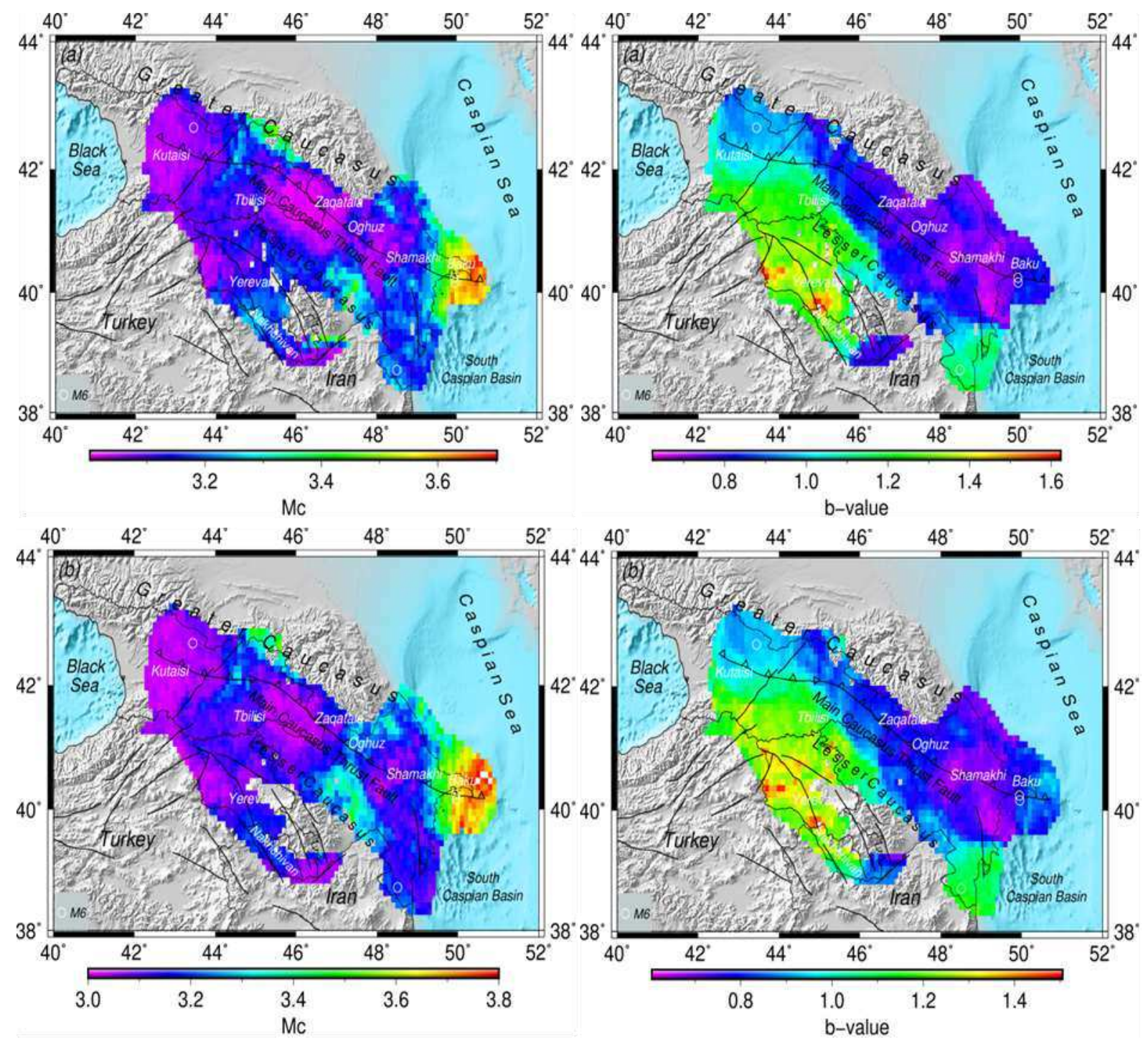

453 Fig. 6 The maps of calculated $b$-value and $M c$ variations from non-declustered (upper) and 454 declustered (bottom) catalogues in the period 1998-2020 in the Caucasus 

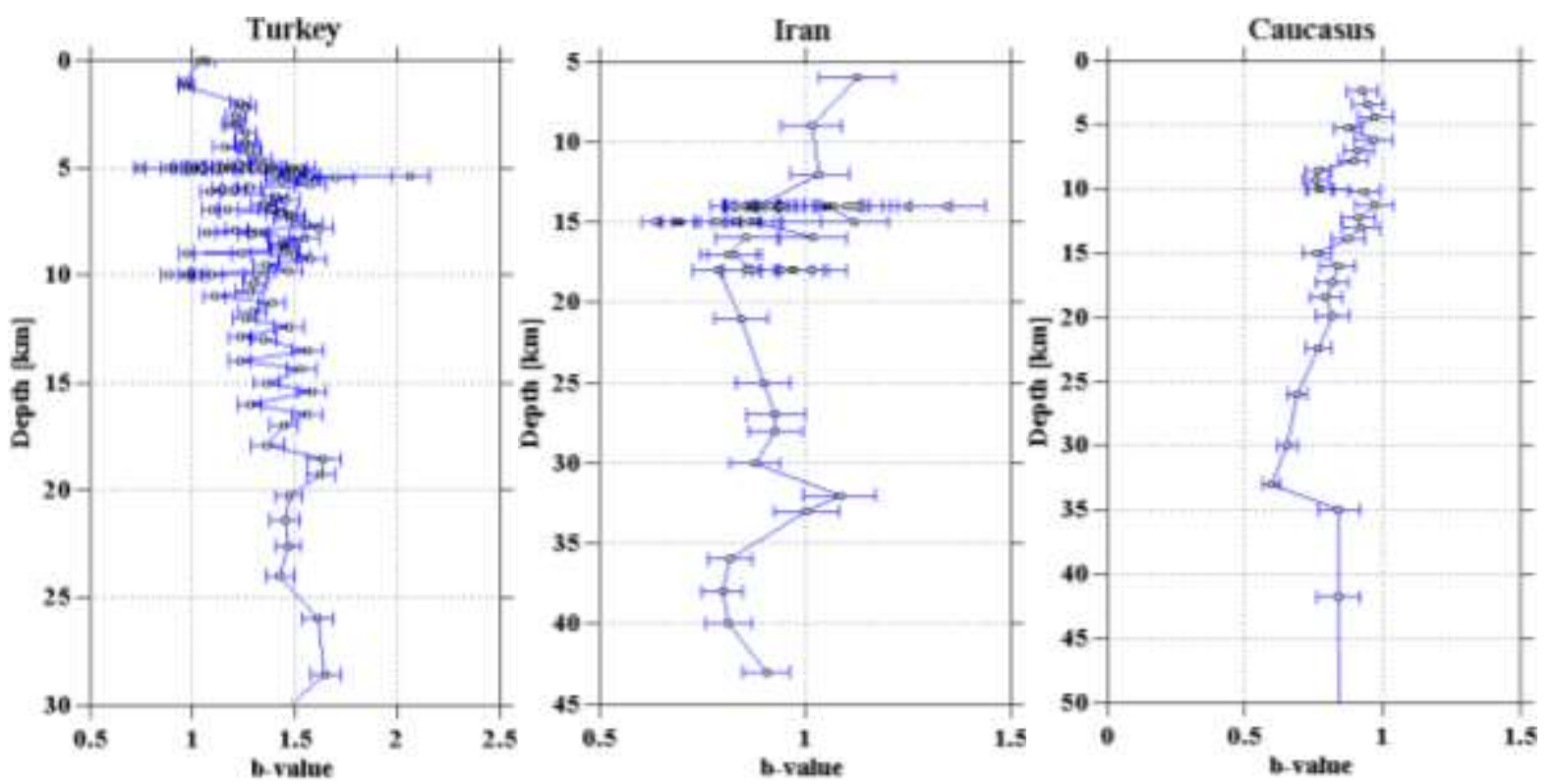

458 Fig. 7 The map shows the calculated value of $b$ and its error (horizontal bar) at a depth 459

460

461

462 

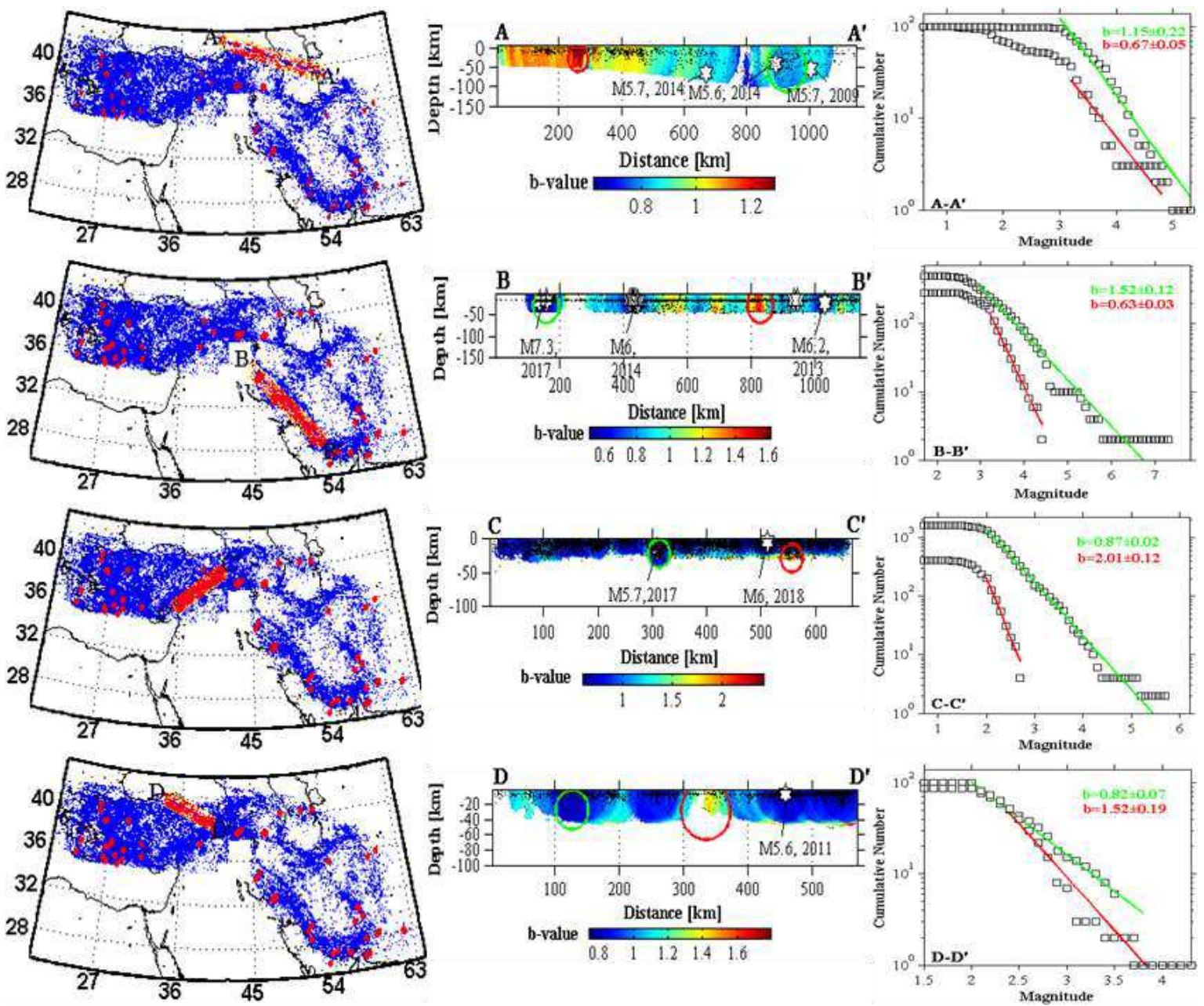

463
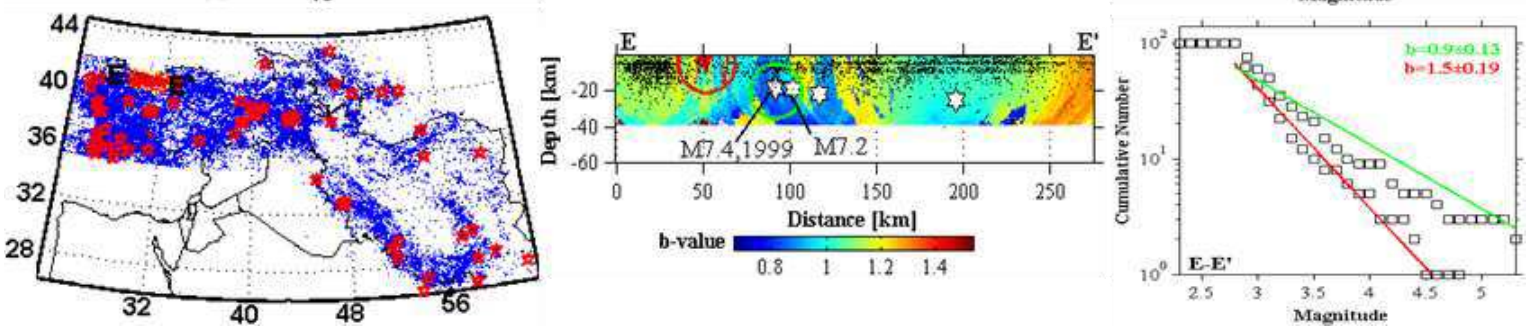

464 Fig. 8 Vertical mapping of $b$-values. The left line shows the intersections. In the middle line, a $b$-value of $150 \mathrm{~km}$ is given around each section. In the right line, the pattern of $b$-value is presented. 


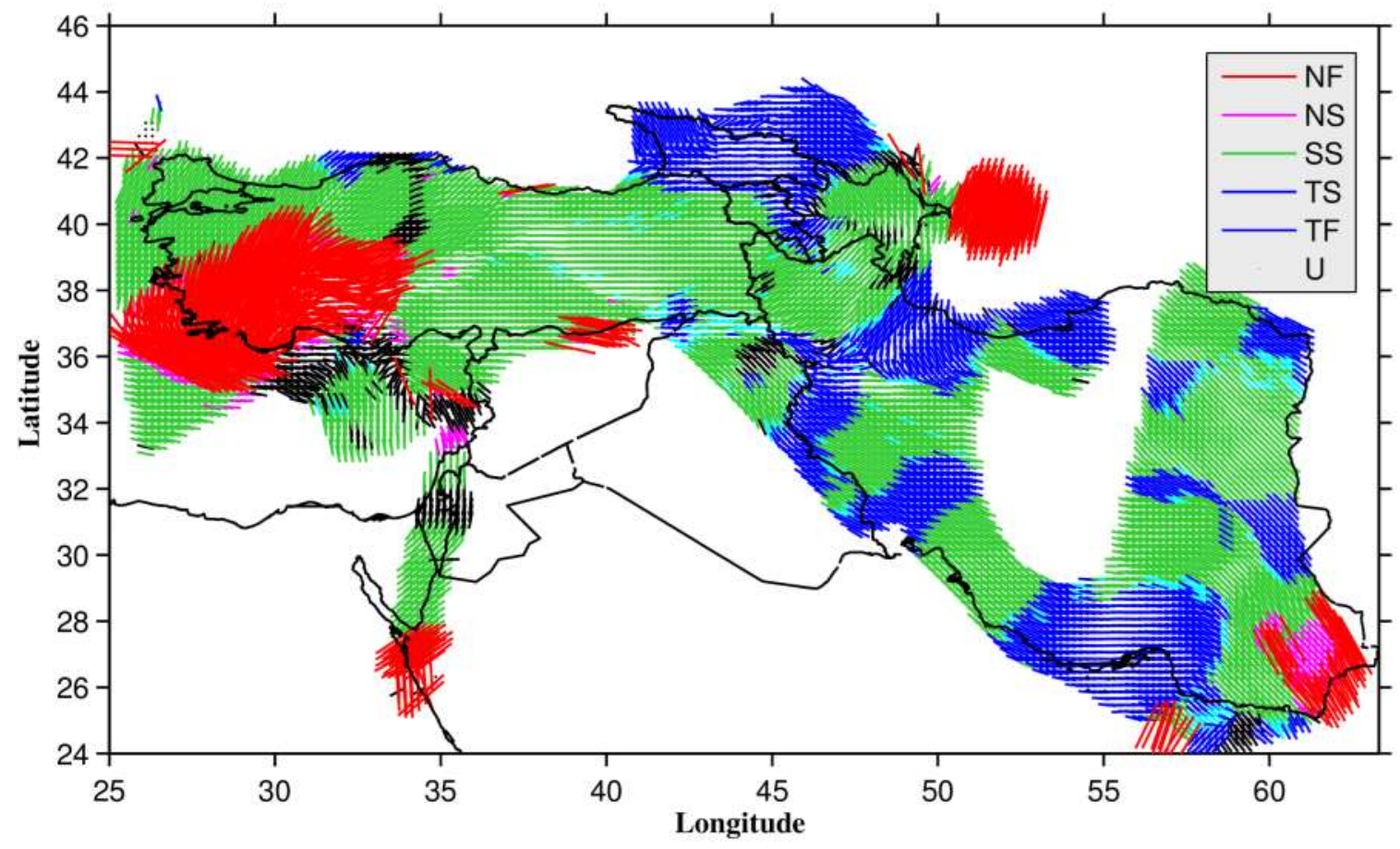

473 Fig. 9 The direction of horizontal compression, different colors symbolize tectonic modes.

474 (NF: Normal, NS: Normal with strike-slip, SS: Strike-slip, TS: Thrust with strike-slip, TF: 475 Thrust).

476

477

478

479 


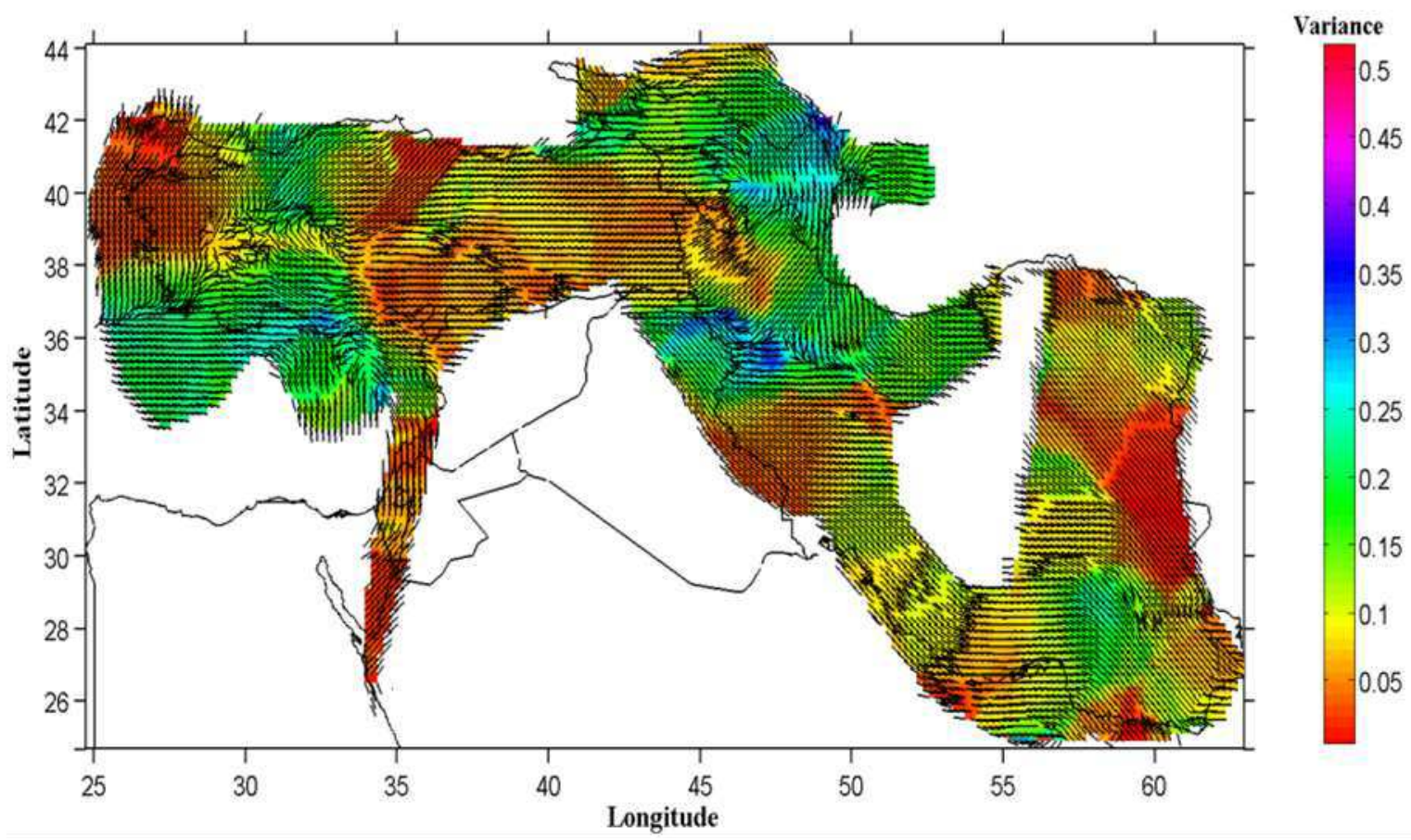

480

Fig. 10 Horizontal compression orientation covered colored stress tensor variance map.

482

483

484

485

486

487

488

489

490

491

492

493 


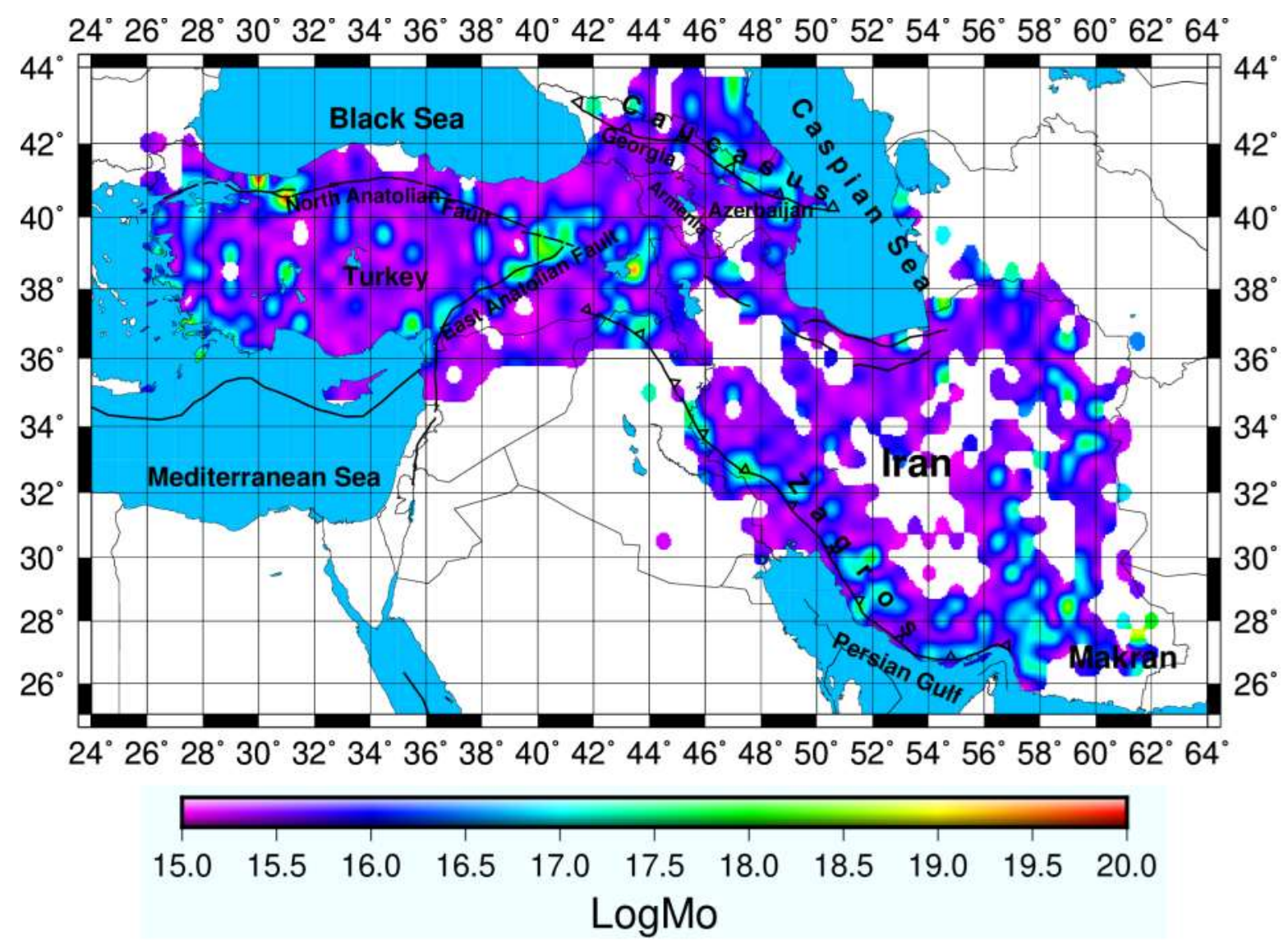

494

Fig. 11 The map shows estimated moment release from the different catalogues from 1998 to 4962020.

497

498

499

500

501

502

503

504

505

506

507 
508 Table 1. Reported strong earthquakes in the research area.

\begin{tabular}{|c|c|c|c|c|c|}
\hline Place & $\begin{array}{c}\text { Date } \\
\text { yy/mm/dd }\end{array}$ & $\begin{array}{c}\text { Longitude } \\
\text { (deg) }\end{array}$ & $\begin{array}{c}\text { Latitude } \\
\text { (deg) }\end{array}$ & $\begin{array}{c}\text { Magnitude } \\
\qquad(\mathrm{Mw})\end{array}$ & $\begin{array}{l}\text { Depth } \\
(\mathrm{km})\end{array}$ \\
\hline Erzincan & $1939 / 12 / 26$ & 39.577 & 39.771 & 7.8 & 20 \\
\hline Gilan & $1990 / 06 / 20$ & 49.409 & 36.957 & 7.4 & 18.5 \\
\hline Erzincan & 1992/03/13 & 39.605 & 39.710 & 6.7 & 27.2 \\
\hline Khorasan & $1997 / 05 / 10$ & 59.809 & 33.825 & 7.3 & 10 \\
\hline Izmit & 1999/08/17 & 29.864 & 40.748 & 7.6 & 17 \\
\hline Düzce & $1999 / 11 / 12$ & 31.161 & 40.758 & 7.2 & 10 \\
\hline Baku & $2000 / 11 / 25$ & 49.946 & 40.245 & 6.2 & 50.4 \\
\hline Van & $2011 / 10 / 23$ & 43.508 & 39.721 & 7.1 & 18 \\
\hline Khash & $2013 / 04 / 16$ & 61.996 & 28.033 & 7.7 & 80 \\
\hline Kermanshah & $2017 / 11 / 12$ & 45.959 & 34.911 & 7.3 & 19 \\
\hline 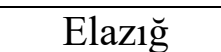 & $2020 / 01 / 24$ & 39.061 & 38.431 & 6.7 & 10 \\
\hline
\end{tabular}




\section{Figures}

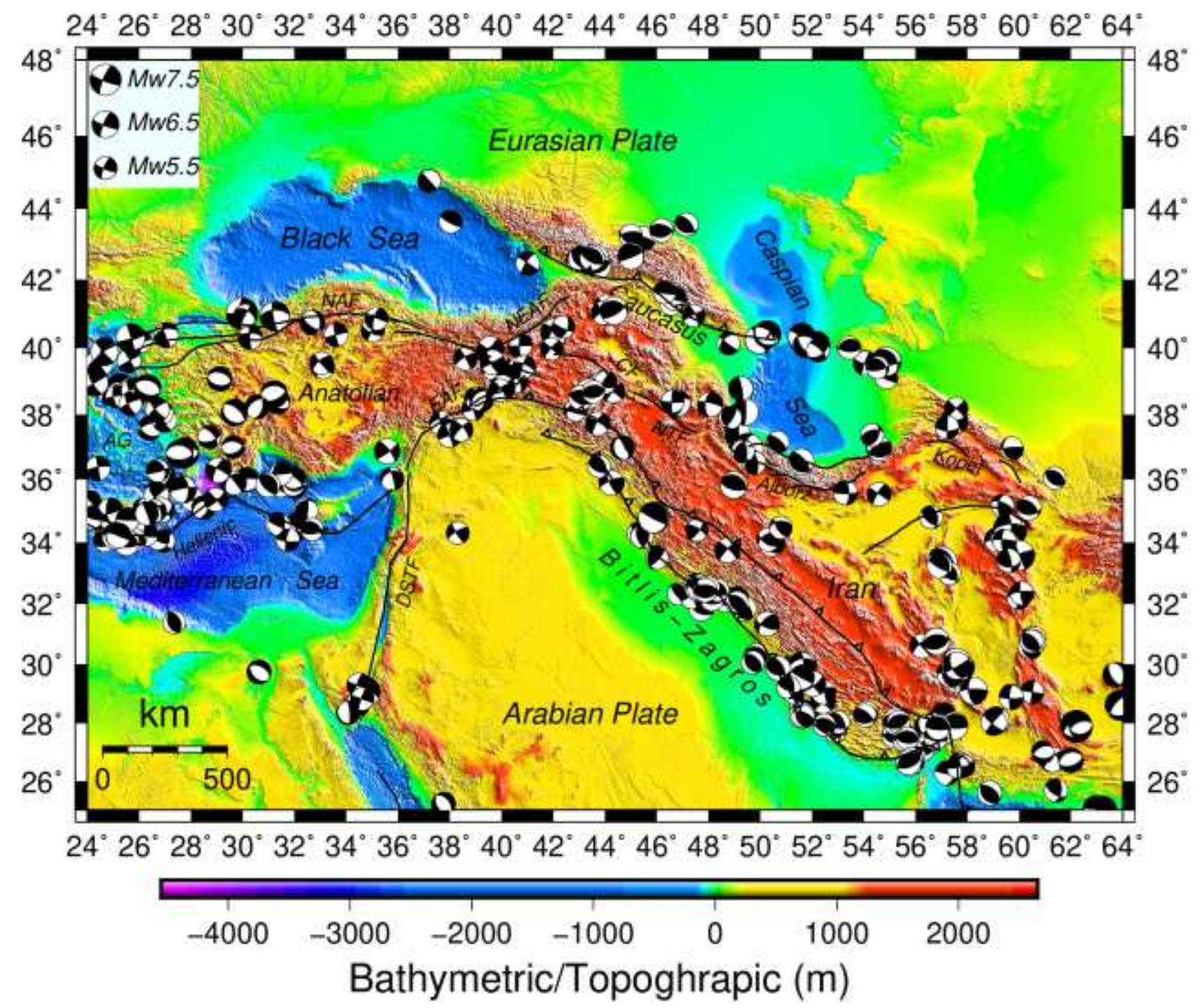

Figure 1

Tectonic and topographic/bathymetric map (SRTM30 plus) of the research area, including the interplay zone of the Eurasian, Arabian and Nubia plates. Abbreviations: AG (Aegean), NAF (North Anatolian Fault), EAF (East Anatolian Fault), DSTF (Dead Sea Transform Fault), NEAF (North-East Anatolian Fault), CF (Chalderan Fault), NTF (North Tabriz Fault). Black beach balls represent the focal mechanism of the earthquakes (M_w $\geq 5.5,1976-2020)$ from global Centroid Moment Tensor CMT). Note: The designations employed and the presentation of the material on this map do not imply the expression of any opinion whatsoever on the part of Research Square concerning the legal status of any country, territory, city or area or of its authorities, or concerning the delimitation of its frontiers or boundaries. This map has been provided by the authors. 


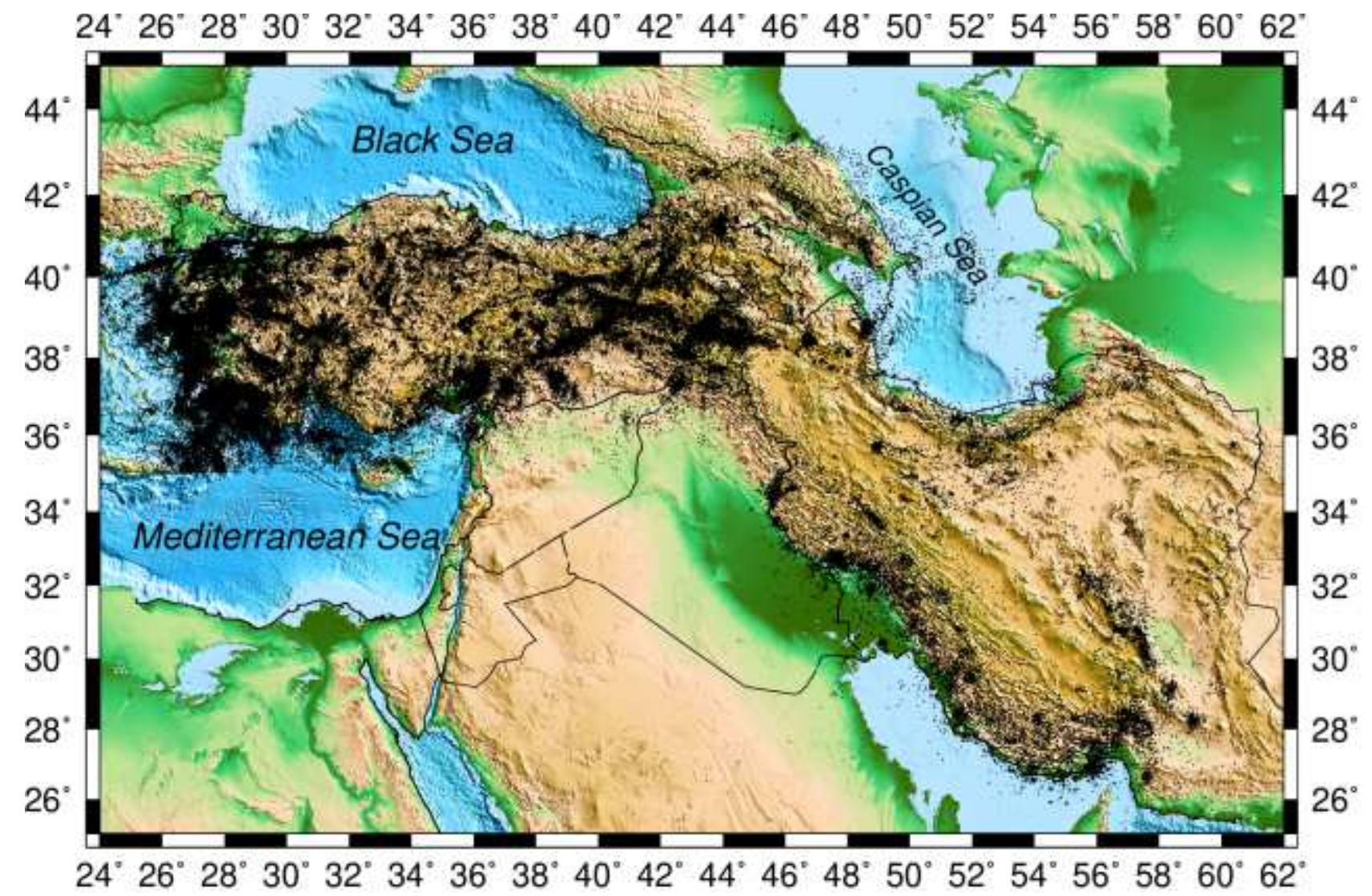

Figure 2

The map represents the distribution of the earthquakes in the study region (1998-2020). Note: The designations employed and the presentation of the material on this map do not imply the expression of any opinion whatsoever on the part of Research Square concerning the legal status of any country, territory, city or area or of its authorities, or concerning the delimitation of its frontiers or boundaries. This map has been provided by the authors. 

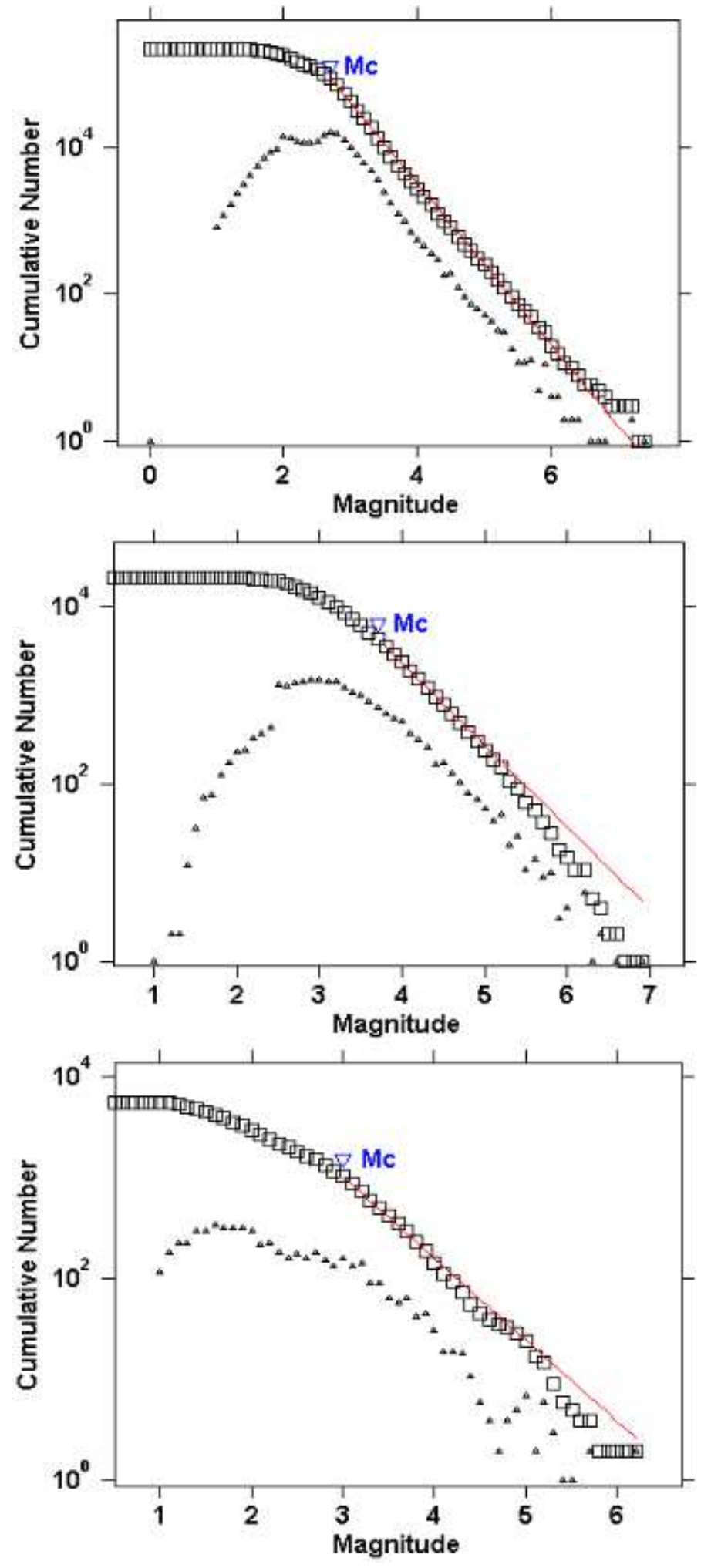

\section{Figure 3}

Frequency-magnitude number of earthquakes from. The solid line and triangle marked as best fit and magnitude of completeness. 

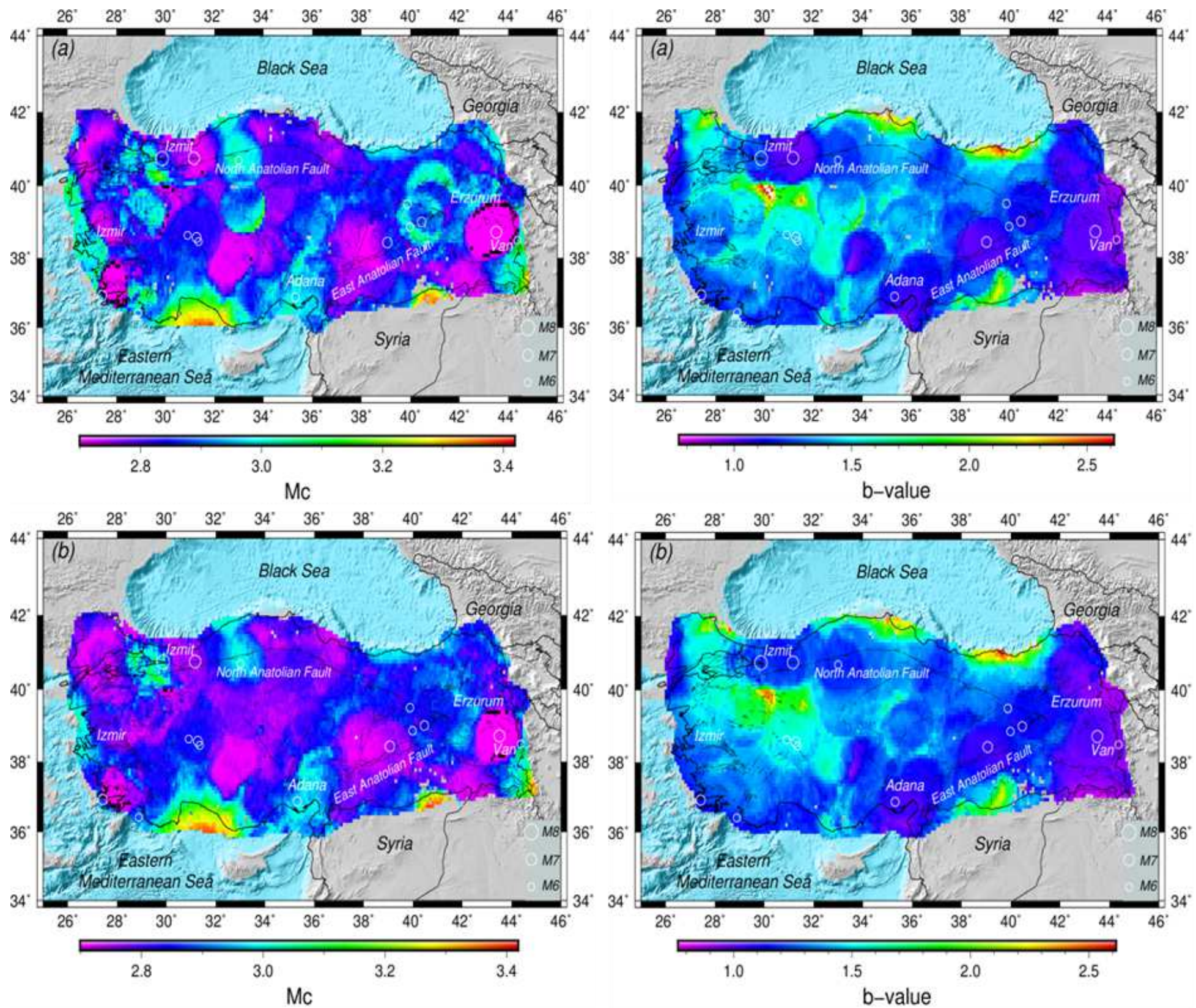

Figure 4

The maps of calculated b-value and Mc variations from non-declustered (upper) and declustered (bottom) catalogues for Turkey in the period of 1998-2020 from KOERI catalogue. Note: The designations employed and the presentation of the material on this map do not imply the expression of any opinion whatsoever on the part of Research Square concerning the legal status of any country, territory, city or area or of its authorities, or concerning the delimitation of its frontiers or boundaries. This map has been provided by the authors. 

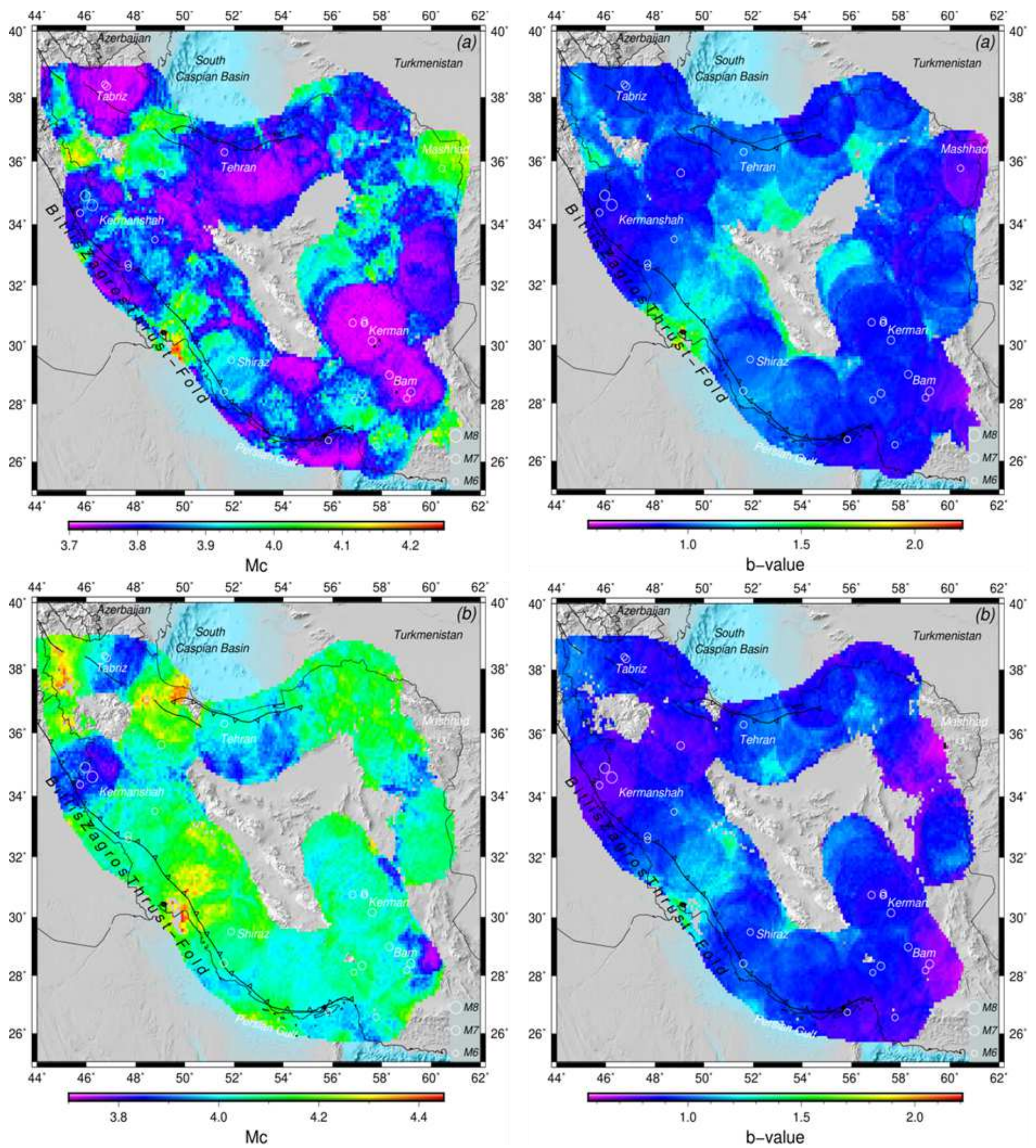

Figure 5

The maps of calculated b-value and Mc variations from non-declustered (upper) and declustered (bottom) catalogues in the period 1998-2020 for Iran using IIEES catalogue. Note: The designations employed and the presentation of the material on this map do not imply the expression of any opinion whatsoever on the part of Research Square concerning the legal status of any country, territory, city or 
area or of its authorities, or concerning the delimitation of its frontiers or boundaries. This map has been provided by the authors.
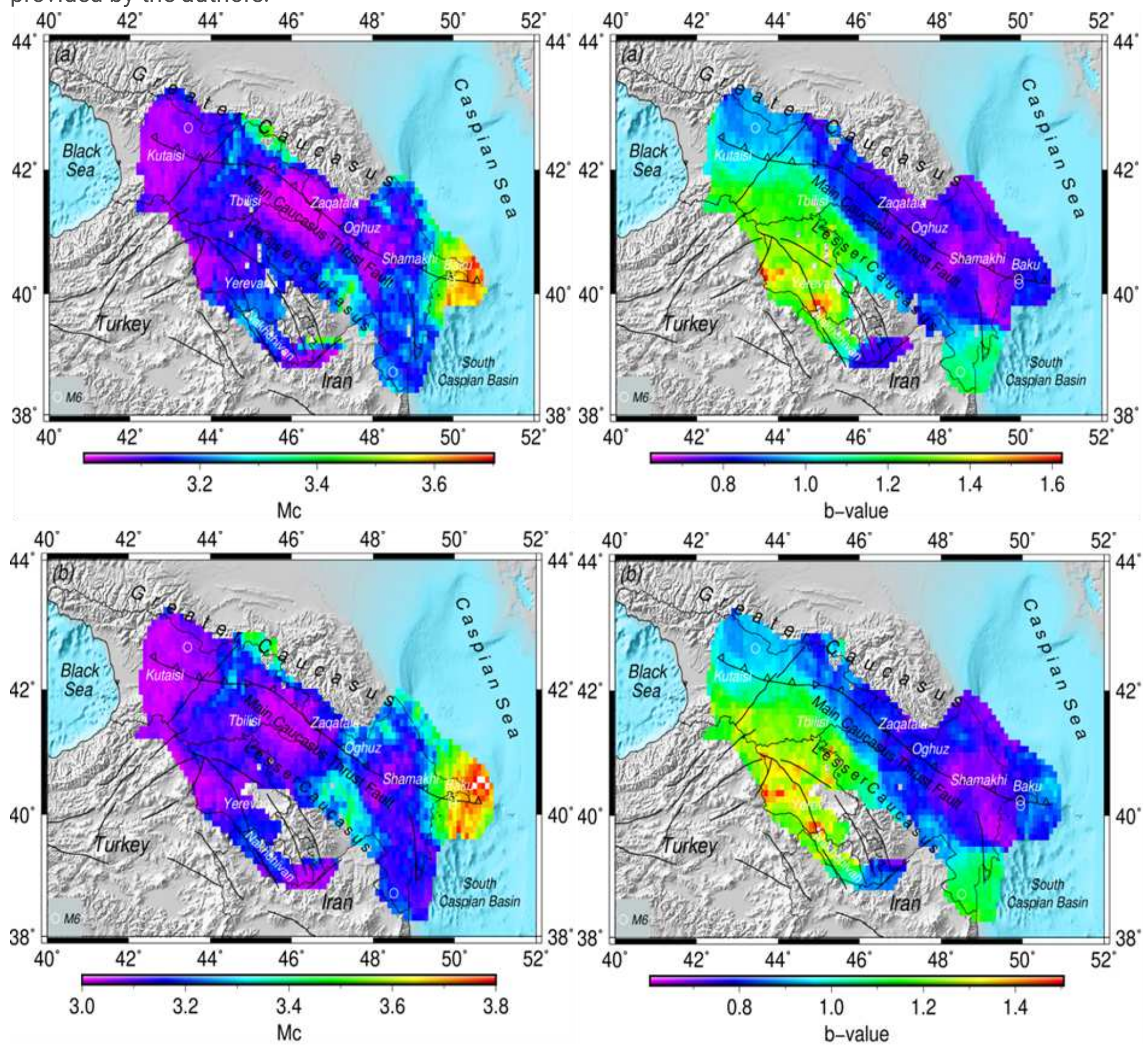

Figure 6

The maps of calculated b-value and Mc variations from non-declustered (upper) and declustered (bottom) catalogues in the period 1998-2020 in the Caucasus. Note: The designations employed and the presentation of the material on this map do not imply the expression of any opinion whatsoever on the part of Research Square concerning the legal status of any country, territory, city or area or of its authorities, or concerning the delimitation of its frontiers or boundaries. This map has been provided by the authors. 

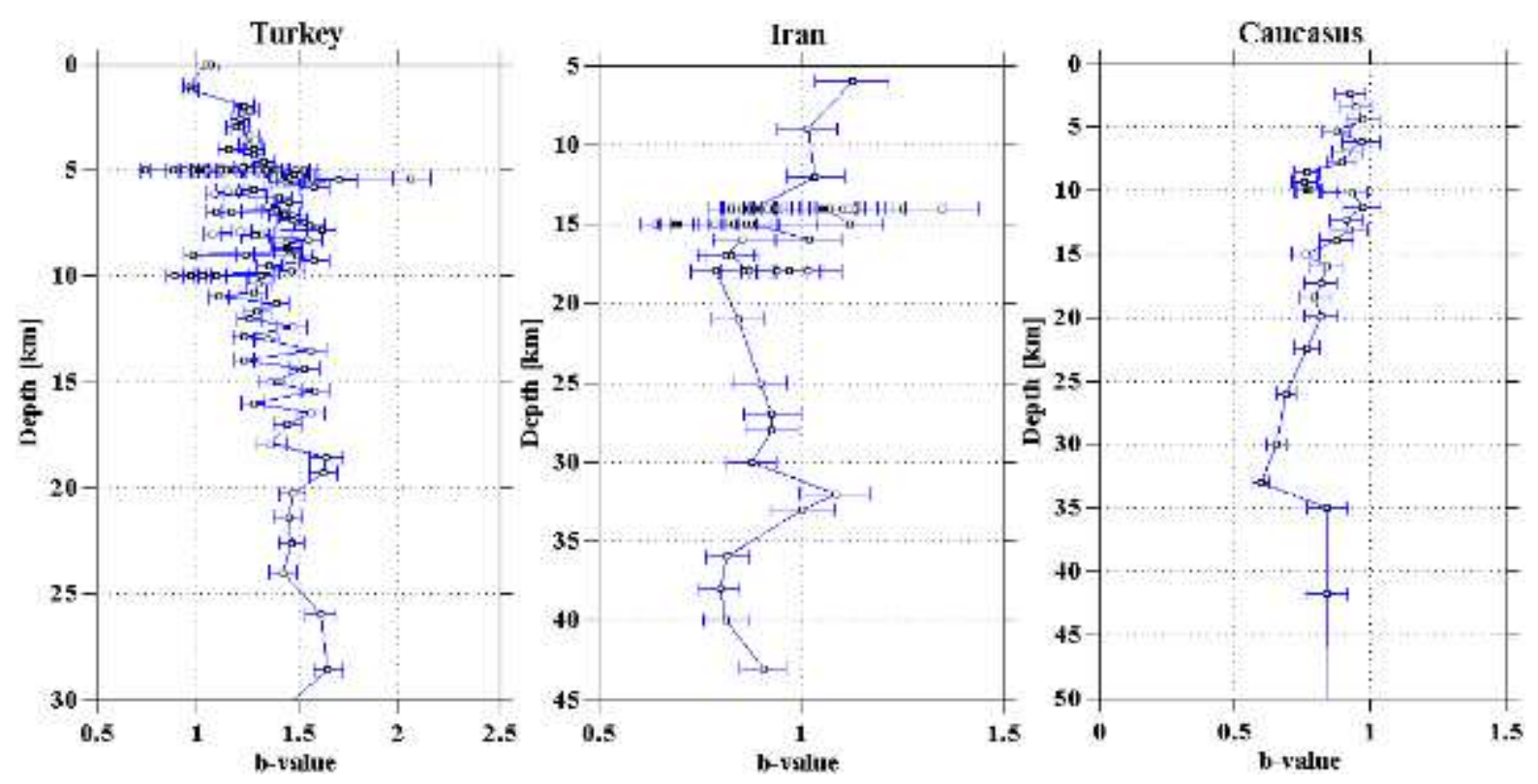

Figure 7

The map shows the calculated value of $b$ and its error (horizontal bar) at a depth. Note: The designations employed and the presentation of the material on this map do not imply the expression of any opinion whatsoever on the part of Research Square concerning the legal status of any country, territory, city or area or of its authorities, or concerning the delimitation of its frontiers or boundaries. This map has been provided by the authors. 

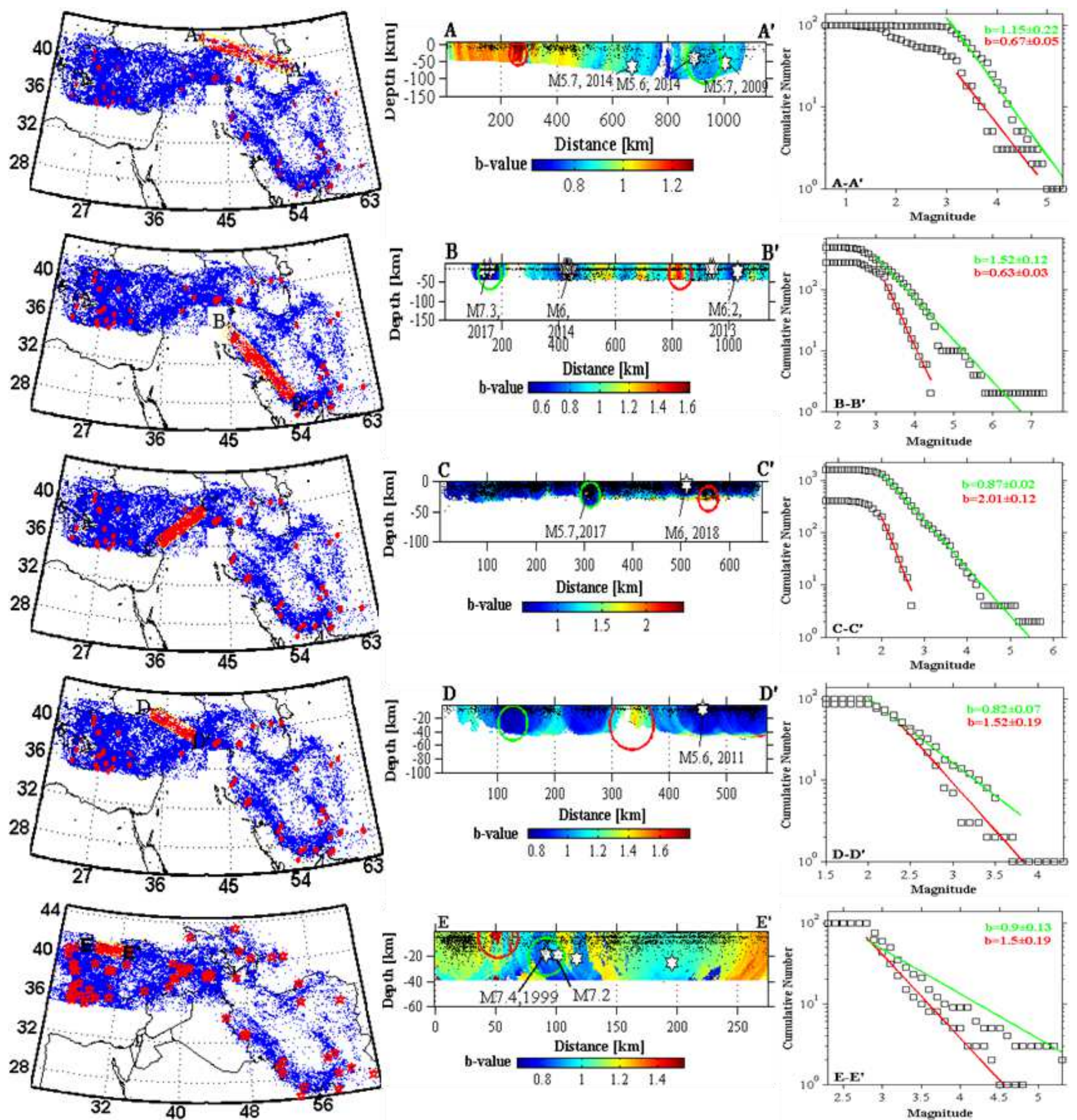

Figure 8

Vertical mapping of b-values. The left line shows the intersections. In the middle line, a b-value of $150 \mathrm{~km}$ is given around each section. In the right line, the pattern of b-value is presented. Note: The designations employed and the presentation of the material on this map do not imply the expression of any opinion whatsoever on the part of Research Square concerning the legal status of any country, territory, city or 
area or of its authorities, or concerning the delimitation of its frontiers or boundaries. This map has been provided by the authors.

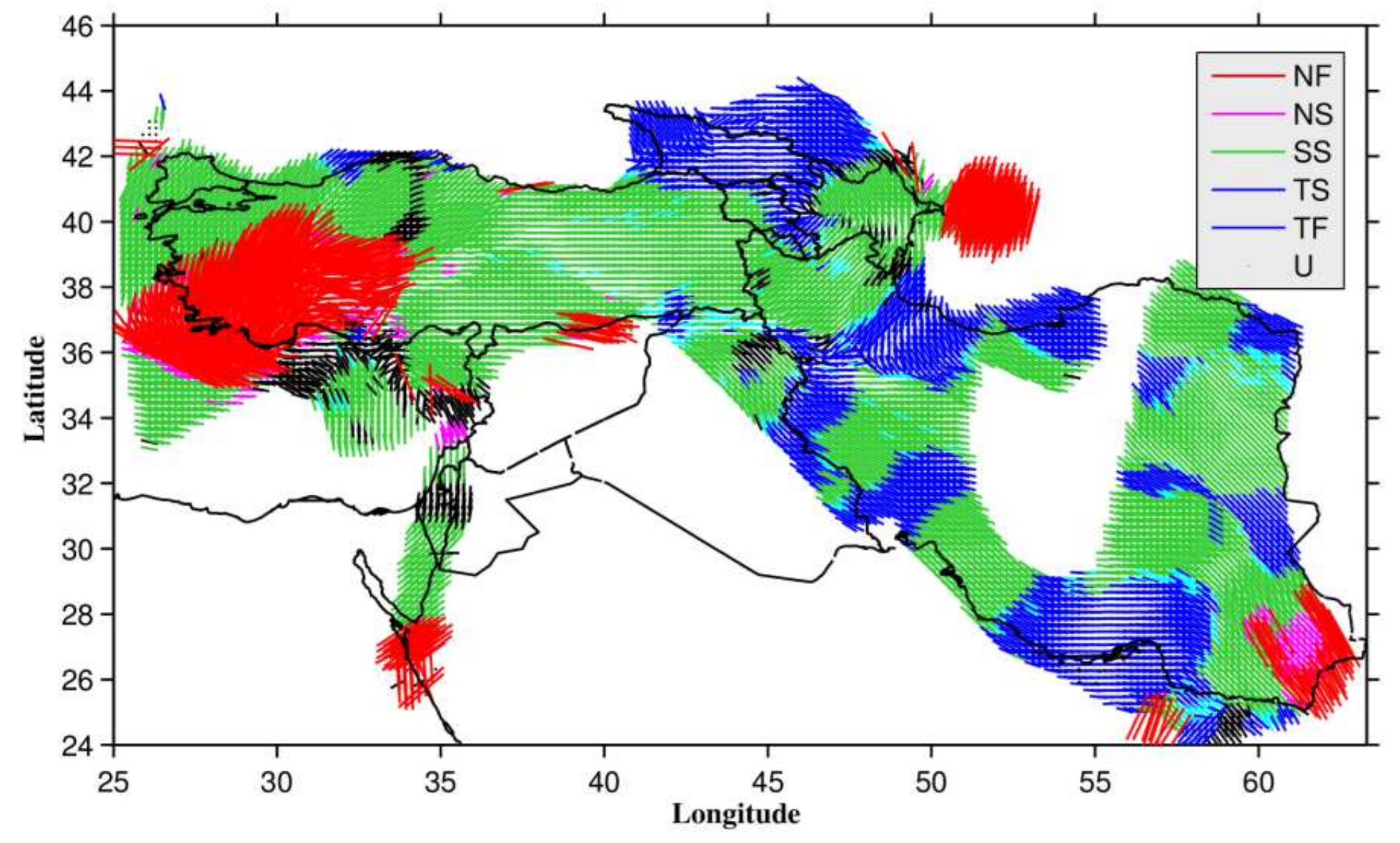

Figure 9

The direction of horizontal compression, different colors symbolize tectonic modes. (NF: Normal, NS: Normal with strike-slip, SS: Strike-slip, TS: Thrust with strike-slip, TF: Thrust). Note: The designations employed and the presentation of the material on this map do not imply the expression of any opinion whatsoever on the part of Research Square concerning the legal status of any country, territory, city or area or of its authorities, or concerning the delimitation of its frontiers or boundaries. This map has been provided by the authors. 


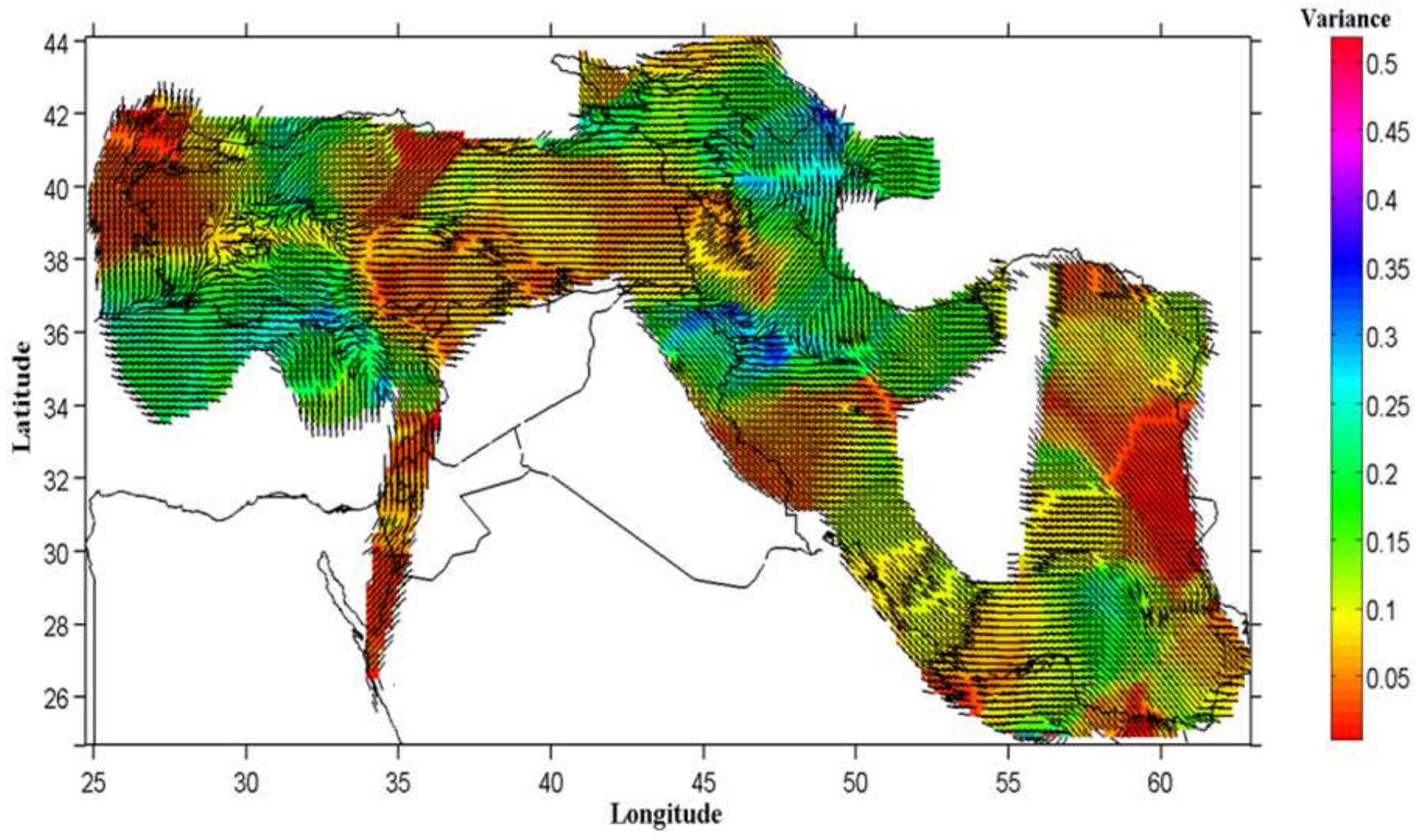

Figure 10

Horizontal compression orientation covered colored stress tensor variance map. Note: The designations employed and the presentation of the material on this map do not imply the expression of any opinion whatsoever on the part of Research Square concerning the legal status of any country, territory, city or area or of its authorities, or concerning the delimitation of its frontiers or boundaries. This map has been provided by the authors. 
$24^{\circ} 26^{\circ} 28^{\circ} 30^{\circ} 32^{\circ} 34^{\circ} 36^{\circ} 38^{\circ} 40^{\circ} 42^{\circ} 44^{\circ} 46^{\circ} 48^{\circ} 50^{\circ} 52^{\circ} 54^{\circ} 56^{\circ} 58^{\circ} 60^{\circ} 62^{\circ} 64^{\circ}$

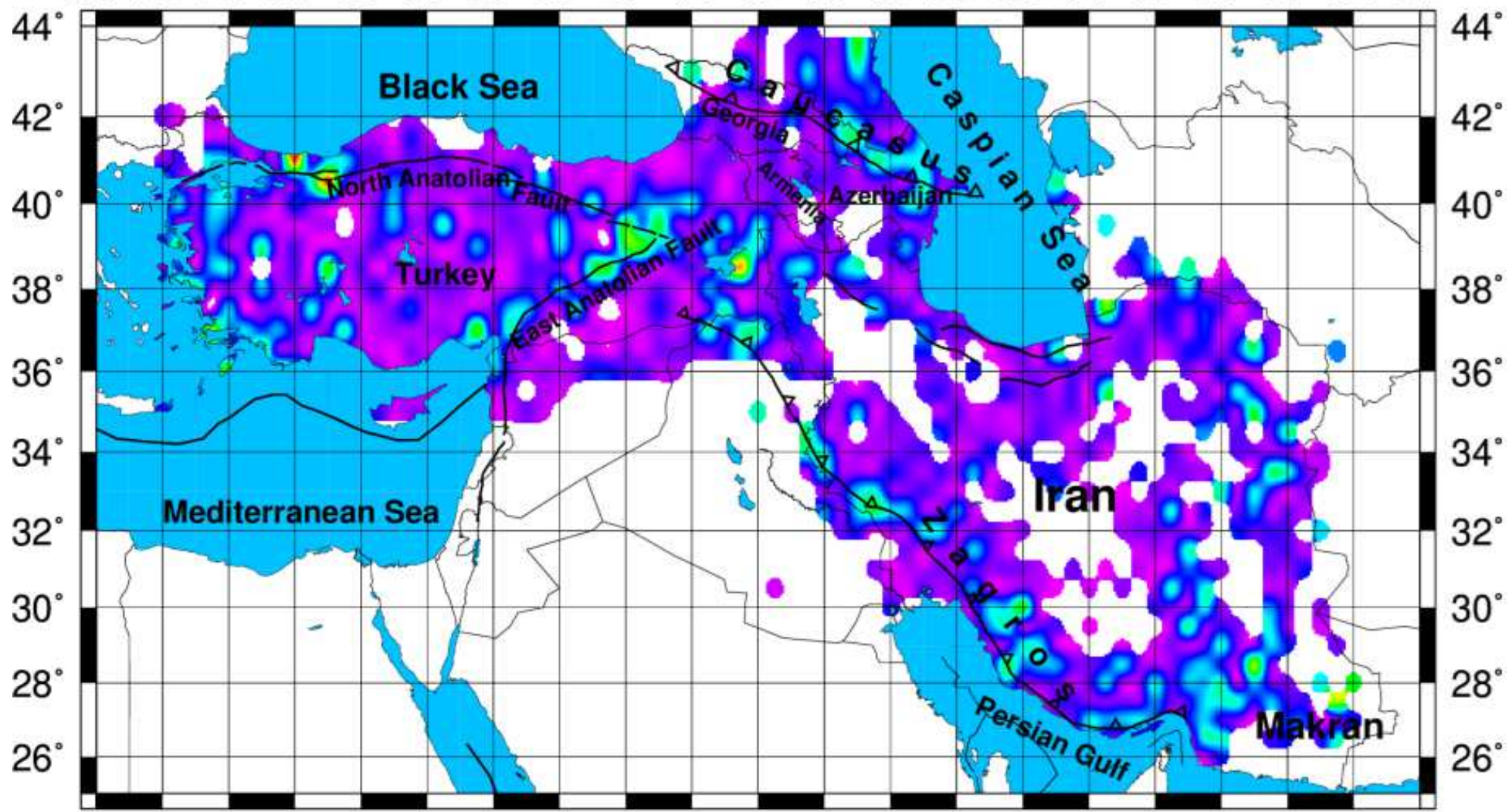

$24^{\circ} 26^{\circ} 28^{\circ} 30^{\circ} 32^{\circ} 34^{\circ} 36^{\circ} 38^{\circ} 40^{\circ} 42^{\circ} 44^{\circ} 46^{\circ} 48^{\circ} 50^{\circ} 52^{\circ} 54^{\circ} 56^{\circ} 58^{\circ} 60^{\circ} 62^{\circ} 64^{\circ}$

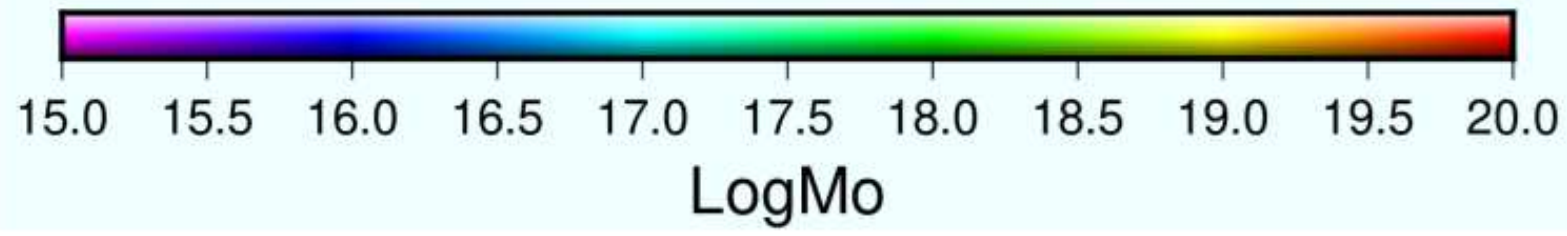

Figure 11

The map shows estimated moment release from the different catalogues from 1998 to 2020 . Note: The designations employed and the presentation of the material on this map do not imply the expression of any opinion whatsoever on the part of Research Square concerning the legal status of any country, territory, city or area or of its authorities, or concerning the delimitation of its frontiers or boundaries. This map has been provided by the authors. 